\title{
Balloon-borne match measurements of midlatitude cirrus clouds
}

\author{
A. Cirisan ${ }^{1}$, B. P. Luo ${ }^{1}$, I. Engel ${ }^{1, *}$, F. G. Wienhold ${ }^{1}$, M. Sprenger ${ }^{1}$, U. K. Krieger ${ }^{1}$, U. Weers ${ }^{1}$, G. Romanens ${ }^{2}$, \\ G. Levrat ${ }^{2}$, P. Jeannet ${ }^{2}$, D. Ruffieux ${ }^{2}$, R. Philipona ${ }^{2}$, B. Calpini ${ }^{2}$, P. Spichtinger ${ }^{3}$, and T. Peter ${ }^{1}$ \\ ${ }^{1}$ Atmospheric and Climate Science, ETH Zurich, Zurich, Switzerland \\ ${ }^{2}$ Federal Office of Meteorology and Climatology MeteoSwiss, Chemin de l'Aérologie, Payerne, Switzerland \\ ${ }^{3}$ Institute for Atmospheric Physics, Johannes Gutenberg University Mainz, Mainz, Germany \\ *now at: Institut für Energie- und Klimaforschung - Stratosphäre (IEK-7), Forschungszentrum Jülich, Jülich, Germany
}

Correspondence to: A. Cirisan (ana.cirisan@alumni.ethz.ch)

Received: 16 July 2013 - Published in Atmos. Chem. Phys. Discuss.: 2 October 2013

Revised: 20 May 2014 - Accepted: 27 May 2014 - Published: 18 July 2014

\begin{abstract}
Observations of high supersaturations with respect to ice inside cirrus clouds with high ice water content $\left(>0.01 \mathrm{~g} \mathrm{~kg}^{-1}\right)$ and high crystal number densities $\left(>1 \mathrm{~cm}^{-3}\right)$ are challenging our understanding of cloud microphysics and of climate feedback processes in the upper troposphere. However, single measurements of a cloudy air mass provide only a snapshot from which the persistence of ice supersaturation cannot be judged. We introduce here the "cirrus match technique" to obtain information about the evolution of clouds and their saturation ratio. The aim of these coordinated balloon soundings is to analyze the same air mass twice. To this end the standard radiosonde equipment is complemented by a frost point hygrometer, "SnowWhite", and a particle backscatter detector, "COBALD" (Compact Optical Backscatter AerosoL Detector). Extensive trajectory calculations based on regional weather model COSMO (Consortium for Small-Scale Modeling) forecasts are performed for flight planning, and COSMO analyses are used as a basis for comprehensive microphysical box modeling (with grid scale of 2 and $7 \mathrm{~km}$, respectively). Here we present the results of matching a cirrus cloud to within 2-15 km, realized on 8 June 2010 over Payerne, Switzerland, and a location $120 \mathrm{~km}$ downstream close to Zurich. A thick cirrus cloud was detected over both measurement sites. We show that in order to quantitatively reproduce the measured particle backscatter ratios, the smallscale temperature fluctuations not resolved by COSMO must be superimposed on the trajectories. The stochastic nature of the fluctuations is captured by ensemble calculations. Possibilities for further improvements in the agreement with the measured backscatter data are investigated by assuming a
\end{abstract}

very slow mass accommodation of water on ice, the presence of heterogeneous ice nuclei, or a wide span of (spheroidal) particle shapes. However, the resulting improvements from these microphysical refinements are moderate and comparable in magnitude with changes caused by assuming different regimes of temperature fluctuations for clear-sky or cloudysky conditions, highlighting the importance of proper treatment of subscale fluctuations. The model yields good agreement with the measured backscatter over both sites and reproduces the measured saturation ratios with respect to ice over Payerne. Conversely, the $30 \%$ in-cloud supersaturation measured in a massive $4 \mathrm{~km}$ thick cloud layer over Zurich cannot be reproduced, irrespective of the choice of meteorological or microphysical model parameters. The measured supersaturation can only be explained by either resorting to an unknown physical process, which prevents the ice particles from consuming the excess humidity, or - much more likely - by a measurement error, such as a contamination of the sensor housing of the SnowWhite hygrometer by a precipitation drop from a mixed-phase cloud just below the cirrus layer or from some very slight rain in the boundary layer. This uncertainty calls for in-flight checks or calibrations of hygrometers under the special humidity conditions in the upper troposphere.

\section{Introduction}

Cirrus clouds play an important role in the complex mechanisms of climate change (Solomon et al., 2007). Their ability to reflect, transmit and absorb solar radiation and to absorb 
and emit infrared terrestrial radiation impacts the terrestrial radiation balance (Mason, 2002). Depending on optical thickness and altitude, as well as on the albedo of the surface or lower clouds, the net effect on climate can either be a cooling or warming (Chen et al., 2000; Fusina et al., 2007; Corti and Peter, 2009), but quantifying the magnitude of this effect is difficult because of uncertainties in these or other quantities characterizing the cirrus life cycle (Lynch et al., 2002). Furthermore, microphysical properties such as number density, size and shape of the ice crystals affect the cloud lifetime and radiative properties and thus the humidity of the upper troposphere and lower stratosphere (Jensen and Toon, 1994).

The formation and evolution of cirrus clouds depends strongly on environmental conditions (temperature, cooling rate, relative humidity, wind field etc.), cloud internal dynamics (Marsham and Dobbie, 2005; Fusina and Spichtinger, 2010) and background aerosols that are either liquid and freeze homogeneously (Hoyle et al., 2005; Spichtinger and Gierens, 2009a) or contain a solid and may act as heterogeneous ice nuclei (DeMott et al., 2010). Ice in the upper troposphere is known to nucleate via both pathways, homogeneous freezing of aqueous solution droplets (Koop et al., 2000) or heterogeneous nucleation on solid aerosol particles (DeMott et al., 2003). Both mechanisms, and especially homogeneous freezing, require regions with very low temperatures and high supersaturation with respect to ice. Ice supersaturated regions (ISSRs), i.e., clear air masses with ice supersaturation, are the potential formation regions for cirrus clouds (Gierens and Spichtinger, 2000; Spichtinger et al., 2003a, b). A variety of data sets (satellite, aircraft, radiosondes) and trajectory calculations serve to improve the understanding of ISSRs and cirrus formation (Ovarlez et al., 2000; Comstock et al., 2004; Jensen et al., 2005; Spichtinger et al., 2005; Gettelman et al., 2006; Vömel et al., 2007; Krämer et al., 2009). Although persistent ISSRs in the upper-tropospheric cloudfree air are well understood, very high supersaturations are difficult to comprehend inside thicker cirrus clouds, such as those described here, with high backscatter ratios of 30-200 (see Fig. 5 below) and high supersaturations $\left(\mathrm{RH}_{\text {ice }}>120 \%\right)$ extending over a wide altitude range $(8-12 \mathrm{~km}$; see Fig. $7 \mathrm{~g}$ below). Cirrus clouds with BSR $>100$ contain ice crystal number densities, $n_{\text {ice }}>1 \mathrm{~cm}^{-3}$ (see Fig. $8 \mathrm{~b}$ below). In this case, the equilibrium time for gas-phase depletion is only a few minutes, and we cannot expect persistent supersaturations extending over a wide altitude range. Even though several potential theoretical explanations for persistent supersaturations have been alluded to, this phenomenon and the frequency of its occurrence remain difficult to understand (Peter et al., 2006, 2008). For example, it is known that in the case of heterogeneous freezing occurring first and only few ice crystals forming, the supersaturation would decrease only slowly (Spichtinger and Gierens, 2009b). Recently, Cziczo et al. (2013) provided evidence for the existence of heterogeneous ice nuclei in the midlatitude up- per troposphere. However, as shown by the hygrometer intercomparison campaign AquaVIT (Fahey et al., 2014), instrumental artifacts may also be a partial cause of the observed supersaturations: under static cloud-free conditions, a core group of eight water vapor instruments investigated by AquaVIT were generally within $\pm 10 \%$ of a reference value for water mixing ratios $>10 \mathrm{ppmv}$ (and total air pressures $70-500 \mathrm{hPa}$ ), with some outliers up to $\pm 20 \%$. This translates into an uncertainty in relative humidity with respect to ice, $\mathrm{RH}_{\text {ice }}$, of 10-20\%. While these results prove that significant discrepancies between instruments exist, they were obtained under well-controlled static conditions, which differ from conditions in the field (e.g., because of reduced ventilation of the instruments). Even larger instrumental discrepancies ( $>20 \%$ at $\mathrm{H}_{2} \mathrm{O}$ mixing ratios between 5 and $150 \mathrm{ppmv}$ ) were recently found in airborne measurements during the NASA MACPEX mission reported by Rollins et al. (2014).

Humidity measurements inside cloud-free ISSRs or cirrus clouds provide normally only an Eulerian measurement, i.e., a snapshot of the investigated air mass. In order to investigate their temporal evolution, a Lagrangian element was introduced in sonde measurements and modeling within the framework of the project LAMMOC (LAgrangian Measurements and MOdeling of Cirrus clouds). The main idea of the project was to analyze and understand the life cycle of midlatitude cirrus clouds as well as the occurrence and evolution of $\mathrm{RH}_{\text {ice }}$ inside these clouds by measuring the same air parcels twice within a few hours. Here we discuss balloon-borne cirrus particle backscatter and relative humidity measurements using this so-called "match" technique. The MeteoSwiss radio-sounding site at Payerne $\left(46.813^{\circ} \mathrm{N}\right.$ and $6.943^{\circ} \mathrm{E}$ ) was taken as a fixed starting point for one of the two match soundings. A mobile balloon-sounding unit was then used to launch a second radiosonde about $2 \mathrm{~h}$ later downstream of Payerne within the greater area of Zurich. The aim to measure the same air mass at cirrus level twice by two subsequent soundings is ambitious, and in order to fully account for the Lagrangian point of view, intensive trajectory calculations have been performed for flight planning and analyses. Microphysical box modeling was used to reproduce the atmospheric profiles for the measurement period (starting a few hours upstream) in order to understand the formation and evolution of the observed cirrus cloud.

\section{2 "Match" technique}

The idea for this technique was first coined during ozone loss studies in the Arctic (Rex, 1993; von der Gathen et al., 1995). Within the framework of the European Arctic Stratospheric Ozone Experiment (EASOE), ozone depletion rates were calculated from matches between random balloon soundings, thereby following the evolution of ozone along the trajectories inside the polar vortex. Rex et al. $(1997,1999)$ improved the technique using numerical weather forecast models as 
a tool for air parcel tracking and predicting the optimum time for the launch of the second balloon sonde. During the SOLVE/THESEO-2000 Arctic stratospheric campaign in the winter 1999/2000, Fueglistaler et al. (2002) applied the match technique to trace widespread occurrences of very large $\mathrm{HNO}_{3}$-containing particles in very low number densities, probably composed of nitric acid trihydrate (NAT), back to polar stratospheric clouds (PSCs) with higher number densities occurring on the mesoscale. Using forward trajectories, they were able to connect the mesoscale "mother clouds" to low number density NAT particle populations several days downstream. Lagrangian characterization of air parcels in order to quantify the efficiency of dehydration in the tropical tropopause layer (TTL) over the western Pacific was conducted as part of the Soundings of Ozone and Water in the Equatorial Region (SOWER) project using frost point hygrometers (Hasebe et al., 2007; Inai et al., 2013). The water vapor match determined from the SOWER network observations was chosen based on isentropic trajectories calculated from the ECMWF operational analysis data, fulfilling temperature and ozone mixing ratio criteria. Finally, Dionisi et al. (2013) used the match method to estimate cirrus crystal fall velocity from ground-based lidar observations. Several attempts to investigate the temporal evolution of cirrus clouds during the aircraft campaigns (Gultepe and Starr, 1995; Field et al., 2006) and using satellite measurements (Soden, 2004) reveal how challenging the Lagrangian measurements are.

In the present work, we perform what is likely the first balloon-borne cirrus match study over midlatitudes. Favorable cirrus match conditions are determined from the following criteria. The balloon launch requires a general alignment of the wind direction as the first criterion in order to minimize the travel distance of the mobile equipment for the downstream measurement. Secondly, a forecast relative humidity with respect to ice exceeding $90 \%$ in the cirrus altitude region is demanded as a prerequisite of cloud existence. Thirdly, the wind speed needs to be sufficiently low to allow for at least $1 \mathrm{~h}$ between the two launches in order to observe possible changes in supersaturation within the air mass. As a final criterion, wind shear must be sufficiently low.

Extended ice supersaturated regions $\left(\mathrm{RH}_{\mathrm{ice}}>90 \%\right)$ and cirrus clouds (ice water content IWC $>10 \mathrm{mg} \mathrm{H}_{2} \mathrm{O}(\mathrm{kg}$ air $)^{-1}$ ) are determined using nested Consortium for SmallScale Modeling (COSMO)/European Centre for MediumRange Weather Forecasts (ECMWF) forecasts. The localization of the downstream match point is based on forecasts from COSMO-2, i.e., the $2 \mathrm{~km}$ resolution version of the regional weather forecast model COSMO, which we retrieved every $3 \mathrm{~h}$. By means of trajectory ensemble calculations based on the COSMO-2 forecasts, we investigated whether match distances (quantifying the tolerance for spatial coincidence) better than $10 \mathrm{~km}$ could be reached in the layer relevant for cirrus formation.
The two matching balloon soundings are established as follows (Fig. 1):

a. Flight trajectory of the upstream radiosonde: the ascent flight path of the first balloon is simulated as the forward trajectory by superimposing a fixed $5 \mathrm{~m} \mathrm{~s}^{-1}$ climb rate onto the COSMO wind field in order to obtain the position of the radiosonde at cirrus altitude.

b. Ensemble of air parcel trajectories: positions along the upstream radiosonde flight path are determined at 15 altitudes with a spacing of $300 \mathrm{~m}$ in the $6-12 \mathrm{~km}$ height range. From these points, air parcel forward trajectories are calculated.

c. Flight trajectory of the downstream radiosonde: for each of the 15 air parcel trajectories the backwards balloon trajectories (with superimposed $-5 \mathrm{~m} \mathrm{~s}^{-1}$ climb rate) are calculated to obtain the potential launch site and time.

d. Match quality at higher levels: forward balloon trajectories are then calculated from the potential downstream launch determined under (3) in Fig. 1 to estimate the match quality at higher levels. The launch site is selected according to optimized humidity conditions and match distances (calculated between the potential second balloon ascent and the given air parcel trajectories on isentropic surfaces).

For the preselected altitude the match distance is zero according to the forecast, while above and below this altitude the match worsens due to wind shear. After the flight, the calculations are repeated with meteorological analyses instead of forecast data and with the actual balloon track as recorded by GPS, showing that the preselected match is typically off by 3 or $4 \mathrm{~km}$.

\section{Instruments and models}

The experimental setup consisted of two standard MeteoSwiss balloon radiosondes (Meteolabor SRS C-34, type 64; serial numbers: Payerne 18651, Zurich 17654). The balloons carried payloads of approximately $1800 \mathrm{~g}$, comprised of a SnowWhite hygrometer (from Meteolabor, Switzerland); a COBALD particle backscatter sonde (our own development); and in addition the Rotronic HC2 capacitive polymer sensor and global positioning system (GPS) receiver, which the Swiss weather service has been using operationally since 2011. Meteorological parameters measured by these radiosondes are temperature, pressure and wind extracted from the GPS data. The balloons have typical mean ascent rates of about $5 \mathrm{~m} \mathrm{~s}^{-1}$, reaching altitudes between 30 and $35 \mathrm{~km}$ before burst. During descent, the payload is attached to a parachute, allowing for a potential recovery. 


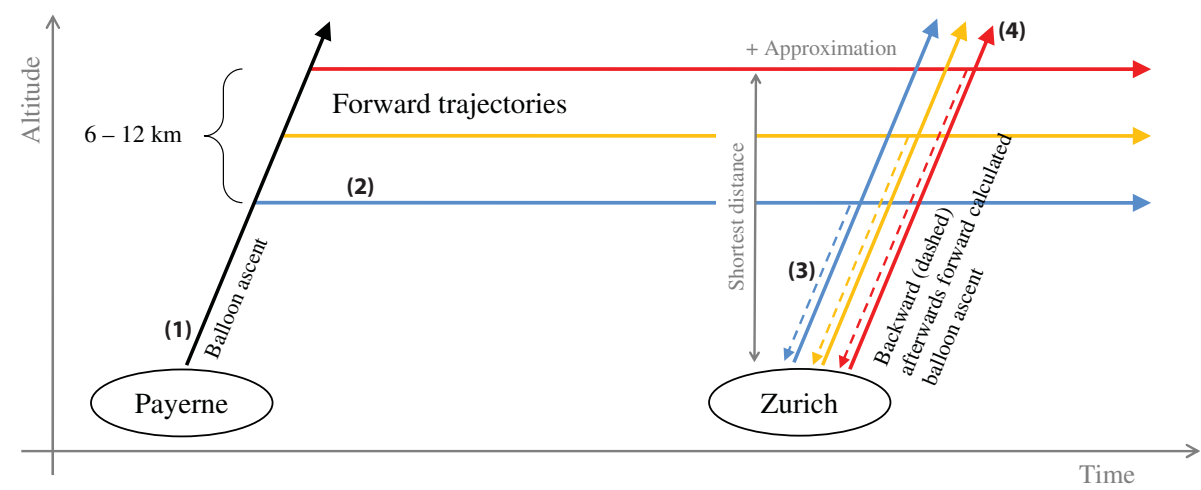

Figure 1. Schematic representation of match procedure. (1) Calculate balloon ascent trajectory from Payerne. (2) Determine the direction of 15 air parcel forward trajectories, starting at points in the cirrus region represented here by three colored horizontal arrows. (3) Calculate backward balloon tracks in the vicinity of the downstream location (close to Zurich) associated with each of the air parcel trajectories. (4) Calculate balloon ascent trajectories from each of the locations in the vicinity of Zurich to estimate the match quality at higher levels (Engel, 2009).

\subsection{COBALD particle backscatter sonde}

The lightweight Compact Optical Backscatter AerosoL Detector (COBALD) was developed recently at the Swiss Federal Institute of Technology (ETH Zurich) to be flown on operational weather balloons (Wienhold, 2012). It has specifications comparable to the Wyoming backscatter sonde by Rosen and Kjome (1991) but implements high-power light emitting diodes (LEDs) in place of the flashlamp. COBALD is much lighter (500 g including batteries) than the Rosen and Kjome sonde $(6 \mathrm{~kg})$. The two LEDs emit light at $455 \mathrm{~nm}$ (blue) and $870 \mathrm{~nm}$ (infrared). A silicon detector measures the light, backscattered by air molecules, aerosols or cloud particles and allows signal retrieval at a higher frequency $(1-20 \mathrm{~Hz})$ than the Rosen and Kjome sonde $(0.15 \mathrm{~Hz})$. Daylight saturates the photodetector, and therefore COBALD measurements are only carried out at night. The geometric overlap between emitted and collected light cones is established at $0.5 \mathrm{~m}$ distance from the instrument, and due to geometry of the optics, the dominant signal contribution is confined to a range of $10 \mathrm{~m}$. COBALD data analysis provides the backscatter ratio (BSR), which is defined as the total signal (from molecules and aerosol particles) divided by the Rayleigh signal (air molecules only; see http://www.iac.ethz.ch/groups/ peter/research/Balloon_soundings/COBALD_sensor for details). In regions with very low aerosol loading the signal consists of almost pure molecular scattering and the BSR is close to unity. The aerosol backscatter ratio (ABSR) is calculated as BSR-1. The color index (CI) is defined as

$\mathrm{CI}=\frac{\operatorname{ABSR}(870 \mathrm{~nm})}{\operatorname{ABSR}(455 \mathrm{~nm})}$

and provides information on the particle size. Using Mie calculations for spherical particles, or the T-matrix method for rotationally symmetric particles (like spheroids), assuming a lognormal aerosol size distribution, CI can be calculated for the wavelengths used by COBALD and then compared with a measured CI in Eq. (1), allowing for an estimate of the particle size. However, due to Mie oscillations, the CI radial dependence becomes non-monotonous, rendering the size attribution ambiguous for radii in excess of $3 \mu \mathrm{m}$. This limits the information concerning the particle size for modeling studies.

\subsection{SnowWhite hygrometer}

The SnowWhite hygrometer is a chilled-mirror sensor developed by Meteolabor AG (Wetzikon, Switzerland). It measures water vapor partial pressure in the atmosphere by means of a dew or frost point measurement (Meteolabor, 2013). SnowWhite has a unique frost/dew point mirror based on a copper-constantan thermocouple, which is Peltiercooled and acts simultaneously as a thermometer, hence minimizing the heat capacity of the system. Regulated to the dew- or frost point temperature of the air directly above the mirror surface, the mirror maintains a thin liquid or solid condensate layer of constant thickness. Changes in the condensate thickness are detected by a phototransistor via an optical fiber (Fujiwara et al., 2003). Relative humidity with respect to ice is calculated based on air temperature and frost point measured temperature, both measured with identical thermocouples. Previous studies have shown some limitations of SnowWhite (Vömel et al., 2007), amongst them the limited frost point depression attainable by the single-stage Peltier cooler under operational conditions (Fujiwara et al., 2003). SnowWhite is being used by some weather services as a reference sonde for the assessing the quality of operational sondes, and has participated in a number of intercomparison campaigns, most recently of which at Observatoire de Haute-Provence (Bock et al., 2013). For our measurements, only the nighttime version of SnowWhite was used, because 
this avoids known problems with the radiative shielding of the daytime version, which may collect hydrometeors, and also because of the requirements for the COBALD sonde.

\subsection{Numerical weather prediction models and trajectory calculations}

For air parcel and balloon trajectory calculations a standard tool for Lagrangian investigations developed at ETH Zurich is used. The Lagrangian Analysis Tool (LAGRANTO; Wernli and Davies, 1997), originally based on ECMWF wind fields, was adapted to the output of the regional Numerical Weather Prediction (NWP) model COSMO for air trajectories and to routines for the balloon trajectory model (Engel, 2009). ECMWF forecasts give a prediction with a horizontal resolution of $25 \mathrm{~km}$, reaching $80 \mathrm{~km}$ altitude with $91 \mathrm{lev}$ els. COSMO- 2 provides a $24 \mathrm{~h}$ forecast for match sounding with the horizontal resolution of $2.2 \mathrm{~km}$ and 60 levels in the vertical, reaching an altitude of approximately $23 \mathrm{~km}$. With the same vertical spacing but $6.6 \mathrm{~km}$ horizontal resolution, COSMO-7 runs are performed for the following $48 \mathrm{~h}$ using a $72 \mathrm{~h}$ forecast. Forecasts longer than three days are provided by ECMWF and used as lateral boundary conditions for the nested COSMO-7. Values are obtained every minute along each trajectory or pathway of a balloon flight for latitude, longitude, altitude, pressure, temperature, potential temperature, water vapor mixing ratio, relative humidity with respect to ice, liquid and ice water content, wind speed and wind direction.

\subsection{Ice microphysics scheme}

The comprehensive Zurich spectral optical and microphysical Lagrangian box model (ZOMM) was used to perform detailed microphysical analyses in order to simulate the formation and evolution processes of the observed cloud. This model has been applied previously for polar stratospheric cloud investigations and tropospheric aerosol and cirrus studies (Luo et al., 2003; Hoyle et al., 2005; Engel et al., 2013). It is also used as a column model, driven by temperature and pressure data along staggered air parcel trajectories (Brabec et al., 2012), and in the present context we will make use of this column feature. Kinetically limited uptake or release of water by ice particles or by aqueous $\left(\mathrm{NH}_{4}\right)_{2} \mathrm{SO}_{4}$ and $\mathrm{H}_{2} \mathrm{SO}_{4}$ solution droplets as well as the ice nucleation of liquid aerosol particles are treated in detail in a Lagrangian approach, i.e., by moving particles in the same size class after growth/evaporation within radius $(r)$ space and avoiding the numerical diffusion that would occur in a Eulerian size scheme with prescribed size bins. Initially the model starts with 100 logarithmically spaced aerosol size classes, but as water uptake and evaporation processes take place, the radius of each size class is allowed to change, and through ice nucleation events, new classes of particles are created (and the corresponding number density of particles will be subtracted from the initial liquid size class). A detailed physical treatment of the ice growth/evaporation process is achieved by numerically solving the diffusion equation, including the option to treat the mass accommodation coefficient (for water molecules on ice) as a function of supersaturation (see below). Concerning nucleation, homogeneous ice nucleation is parameterized based on classical nucleation theory generalized to describe the freezing of aqueous solution droplets implementing the water-activity-based theory of Koop et al. (2000). After each nucleation event a new size class for ice is created. When the ice particles are evaporated, we delete this ice size class and the number density is put back into the original liquid size class from which the ice particles nucleated. Besides homogeneous nucleation the model also calculates heterogeneous ice nucleation on ice nuclei, assumed to be mineral dust particles in the immersion mode, similar to the approach by Engel et al. (2013) using the active-site-based heterogeneous nucleation parameterization of Marcolli et al. (2007). Sedimentation of the ice crystals within the column is taken into account by means of a size-dependent terminal velocity, moving a fraction of them into boxes at lower levels (in vertically stacked Eulerian bins of $100 \mathrm{~m}$ depth). The ice particles are redistributed into the neighboring ice classes if the mass difference between the resulting classes is less than $20 \%$, and this is performed by maintaining mass and number density. Otherwise, a new ice class is created for sedimented ice particles from the upper layer.

\subsection{Optical scheme}

With the aid of a light-scattering algorithm for spherical and non-spherical particles (Mishchenko, 1991) it is possible to convert particle size distributions calculated by the microphysical model into a simulated backscatter sonde signal along the chosen trajectory. The information from the microphysical scheme is used as input for the optical model, which allows for the calculation of backscatter coefficients and depolarization ratios of particles at arbitrary wavelengths, here in particular at the COBALD wavelengths. By comparing the results of the optical simulation with the observed BSR, certain parameters of the microphysical model can be constrained. The scattering matrix of liquid particles is computed exactly by solving the scattering problem by means of Mie theory (Bohren and Huffman, 2010). The refractive index of the aqueous droplets is calculated using the model of Krieger et al. (2000) for $\mathrm{H}_{2} \mathrm{SO}_{4}-\mathrm{H}_{2} \mathrm{O}$ solution droplets. For the calculation of the backscattering by ice particles we use the refractive index of ice (1.31) and apply the T-matrix method by Mishchenko (1991) to estimate shape effects. Here, we approximate the ice particles by prolate ("cigar-like") spheroids with the aspect ratio $A=a / b$ (the ratio of the equatorial to polar lengths) and volume $V=4 / 3 \pi a^{2} b$, which is taken equal to the volume of the ice particles calculated by the microphysical model. Following Brabec et al. (2012), we assume 

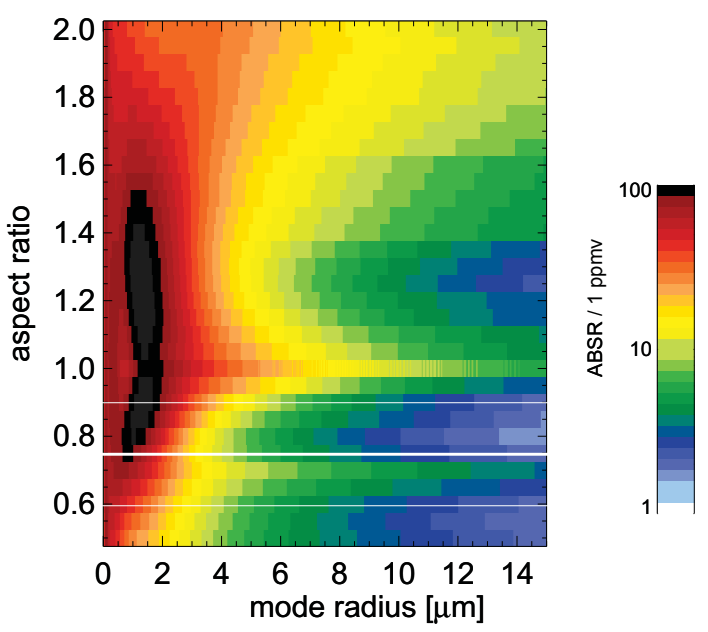

Figure 2. Color diagram depicting aerosol backscatter at $870 \mathrm{~nm}$ calculated by means of the T-matrix method (Mishchenko, 1991) for spheroids as a function of aspect ratio $A$ and equivalent sphere radius $r$. The figure assumes $1 \mathrm{ppmv}$ of $\mathrm{H}_{2} \mathrm{O}$ condensed in the ice phase. Results for other condensed phase mixing ratios can be obtained by linear scaling. Thick white line: $A=0.75$ assumed here. Thin white lines: $\pm 20 \%$ deviations.

an aspect ratio $A=0.75$, i.e., slightly prolate, which may be a typical value for midlatitude cirrus cloud particles. Nousiainen and McFarquhar (2004) found that the small ice crystals with dimension $<100 \mu \mathrm{m}$ are mostly quasi-spherical and $\mathrm{Fu}$ (2007) found that the scattering properties are not sensitive to the aspect ratio. Figure 2 shows the aerosol backscatter ratio, ABSR, as a function of aspect ratio and radius $r=$ $(3 V / 4 \pi)^{1 / 3}$. Within a range of $A$ differing by $\pm 20 \%$ from assumed aspect ratio, for a given $r$, the calculated ABSR may differ from the values at $A=0.75$ by up to a factor of 2 . This uncertainty needs to be taken into account when interpreting the sonde measurements.

\section{Results}

The meteorological conditions of more than 500 nights were analyzed during a $2.5 \mathrm{yr}$ period with respect to the suitability to perform match flights. Of these 500 nights about 30 satisfied the match criteria between Payerne and the greater area of Zurich. Even though there were more days with a favorable match situation, other factors dominated the decisions not to perform the launches, such as ground weather conditions, limited human resources on either site, lacking COSMO-2 forecasts for the scheduled day etc. Match flights were performed during only 9 of these 30 nights (e.g., because the weather situation became favorable only briefly before the required flight time). Three of these nine launches suffered from technical problems during flight caused by one of the GPS receivers or from unexpected launch problems (such as rain). Table 1 shows the dates of the nine match
Table 1. Performed match flights by date and downstream launch location. Closest match distance and closest match altitude for each flight calculated from balloon GPS positions and trajectories based on NWP analysis data (n/a: loss of GPS signal or sonde transmission).

\begin{tabular}{lcccc}
\hline Date & $\begin{array}{c}\text { Latitude } \\
{\left[{ }^{\circ} \mathrm{N}\right]}\end{array}$ & $\begin{array}{c}\text { Longitude } \\
{\left[{ }^{\circ} \mathrm{E}\right]}\end{array}$ & $\begin{array}{c}\text { Match distance } \\
{[\mathrm{km}]}\end{array}$ & $\begin{array}{c}\text { Altitude } \\
{[\mathrm{km}]}\end{array}$ \\
\hline 06.07 .2009 & 47.379 & 8.549 & 3.4 & 9.3 \\
19.11 .2009 & 47.227 & 8.329 & 15.6 & 10.3 \\
16.02 .2010 & 47.379 & 8.549 & 5.7 & 6.0 \\
29.03 .2010 & 47.482 & 7.837 & $\mathrm{n} / \mathrm{a}$ & $\mathrm{n} / \mathrm{a}$ \\
29.04 .2010 & 47.467 & 7.819 & 5.5 & 7.1 \\
08.06 .2010 & 47.453 & 7.988 & 1.7 & 9.4 \\
21.09 .2010 & 47.222 & 8.594 & $\mathrm{n} / \mathrm{a}$ & $\mathrm{n} / \mathrm{a}$ \\
22.10 .2010 & 46.953 & 8.449 & 25.0 & 6.0 \\
25.08 .2011 & 47.435 & 7.658 & $\mathrm{n} / \mathrm{a}$ & $\mathrm{n} / \mathrm{a}$ \\
\hline
\end{tabular}

flights, including information about the location of the downstream sounding in the surrounding of Zurich, the closest obtained match distance and the altitude where this distance occurred. The upstream sounding was always performed from Payerne at $46.81^{\circ} \mathrm{N}, 6.94^{\circ} \mathrm{E}$. Match values are based on balloon GPS data and trajectories from NWP analysis data. GPS-based analyses suggest match distances of a few kilometers (whereas the best distance in a forecast is zero by definition). In what follows we present the match flight case with the best match distance performed on 8 June 2010 .

\subsection{Match forecast and analysis}

The latest available COSMO-2 forecast from 15:00 UTC on 8 June 2010 confirmed a favorable match situation as suggested by ECMWF and COSMO-7 forecasts a few days earlier. Air was approaching Switzerland from the Atlantic Ocean, west of Portugal, in a flow with relatively low horizontal wind shear, and above $8.5 \mathrm{~km}$ also low vertical wind shear (Fig. 3a). The air was moist but cloud-free over the Atlantic, and was forecast to cool, thus resulting in conditions for cirrus formation when approaching Switzerland. The time for the first sounding from Payerne was set, and then the time and location of the second sounding was determined by choosing the best match trajectory that fulfilled the criteria outlined in Sect. 2.

The sounding from Payerne was scheduled for 20:00 UTC, but realized $4 \mathrm{~min}$ later, while the one in the surrounding of Zurich from $47.45^{\circ} \mathrm{N}, 7.85^{\circ} \mathrm{E}$ started exactly at 21:28 UTC, as scheduled. Ground conditions were dry at Payerne, but with episodic, very light drizzling rain at the upstream position, which almost compromised the launch. The location of the second sounding is presented as a red point in Fig. $3 \mathrm{~b}$. The colored curves show the spread in air parcel trajectories for different altitude levels based on the COSMO-2 analysis data starting from the Payerne GPS track, indicating that the trajectory at $9.4 \mathrm{~km}$ yields the best match distance with 

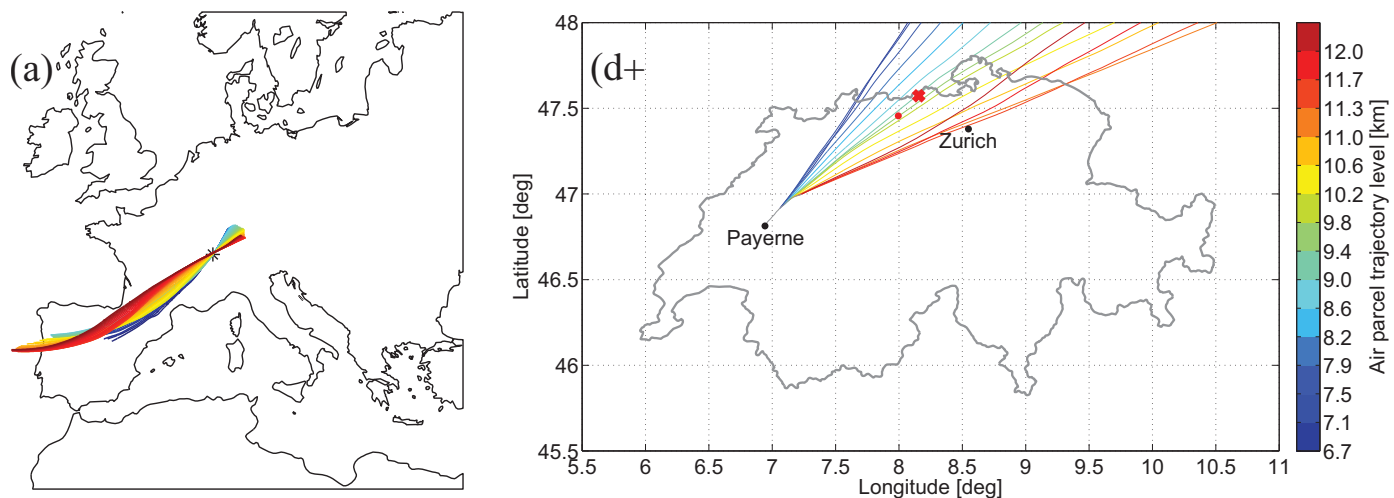

Figure 3. (a) Ensemble of trajectories calculated with the COSMO-7 analysis fields backward and forward in time calculated by LAGRANTO from the track of the balloon started from Payerne (8 June 2010, 20:04 UTC), showing the evolution from $20 \mathrm{~h}$ upstream to $4 \mathrm{~h}$ downstream of Payerne. (b) Air parcel trajectories for different altitude levels calculated using COSMO-2 analyses in combination with the GPS data of the balloon ascent in Payerne. Red dot shows the downstream launch site $\left(47.46^{\circ} \mathrm{N}, 7.99^{\circ} \mathrm{E}\right)$ fitting the trajectory at $9.4 \mathrm{~km}$ altitude that gives the best match distance (about $1.5 \mathrm{~h}$ downstream of Payerne), presented as a red cross $\left(47.57^{\circ} \mathrm{N}, 8.15^{\circ} \mathrm{E}\right)$.

the second balloon launch. The analysis data reveal a relatively low but significant horizontal wind shear, pointing to the highly dynamical processes in the atmosphere, that compromises the column box model approach. The forecast predicted significantly less wind shear than the analysis revealed, namely an angular spread only about half as large as that shown in Fig. 3b. Furthermore, given horizontal wind velocities of $\approx 70 \mathrm{~km} \mathrm{~h}^{-1}$ in $6-12 \mathrm{~km}$ altitude range, the delay of $4 \mathrm{~min}$ in the upstream launch may be responsible for a few kilometers of mismatch.

In order to validate the match accuracy and the quality of the NWP forecast, the air parcels initialized from the GPS balloon track in Payerne and followed by COSMO-2 analysis trajectories are related to the GPS balloon track from the Zurich sounding. Thus the match distances calculated from the forecast and from the analysis are compared. As mentioned before, the simultaneous shortest distance between the air parcel trajectory initialized from the Payerne GPS balloon track and the Zurich balloon GPS recording is calculated on isentropic surfaces for each level. Figure 4 shows these match distances as a function of altitude for COSMO-2 forecast and analysis fields. In the forecast case the smallest match distance between the forecast trajectories and the balloon track is at $9.0 \mathrm{~km}$ altitude, whereas it is at $9.3 \mathrm{~km}$ when using the analysis wind fields. In reality, when replacing the balloon simulation with the GPS balloon tracks, the closest approach to the COSMO-2 analysis trajectories is at $9.4 \mathrm{~km}$ altitude with a distance of $1.7 \mathrm{~km}$. This confirms that the forecasting tool is successful in matching the target air parcel with a distance better than a few kilometers.

\subsection{Observations}

Figure 5 shows the radiosonde profiles for the night of 8 June 2010. COBALD measurements are presented by the backscatter ratios at $870 \mathrm{~nm}$ wavelength (red line), whereas

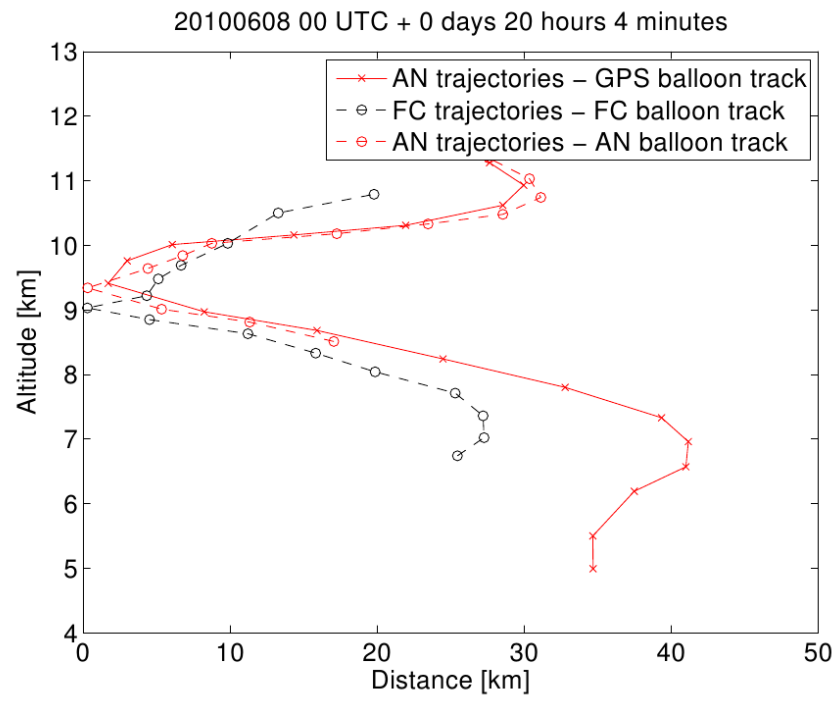

Figure 4. Match distances between air parcel and the balloon trajectories based on different data sets. Forward trajectories are computed with COSMO-2 forecast (FC) and analysis (AN) at the same potential temperature level and point in time.

SnowWhite measurements are shown as $\mathrm{RH}_{\text {ice }}$ (cyan, above $\approx 3.5 \mathrm{~km}$ ). As expected, the Rotronic HC2 sensor (dark-blue dashed) provides good $\mathrm{RH}_{\text {ice }}$ up to about 6 or $7 \mathrm{~km}$ altitude, but it becomes too slow to follow the moisture structure at higher levels, as is strikingly clear from the sudden drop in humidity at the tropopause captured well by SnowWhite. Therefore, the subsequent analysis will be mainly based on the SnowWhite measurements. The error analysis for COBALD limits its uncertainty to $\pm 8-10 \%$ of backscatter ratio at $870 \mathrm{~nm}$. For SnowWhite, the nominal uncertainty is $\pm 3 \%$. However, as can be seen below, the accuracy in one of the measurements was most likely severely compromised, 
leading to a systematic error of more likely 20-30\%. Indeed, in Sect. 4.4.6 we will largely dismiss the large and persistent supersaturations implied by the SnowWhite sounding over Zurich. This does not affect the discussion of modelmeasurement differences in aerosol backscatter, which comprise a major focus of the paper.

The BSR approaches values close to unity (molecular Rayleigh backscatter) in layers with very low aerosol concentrations, i.e., around $4.5 \mathrm{~km}$ altitude and in the lower stratosphere. Conversely, there is a thick cloud layer above both sites between 6 and $13 \mathrm{~km}$, with particle sizes larger than $3 \mu \mathrm{m}$ indicated by the CI $>15$ (not shown here). The humidity and temperature measurements suggest that the observed thick cloud consisted of a mixed-phase cloud below $7.5 \mathrm{~km}$ altitude and a cirrus cloud above, which we will show to be consistent with box model simulations. Between 3 and $4 \mathrm{~km}$ another broad peak in BSR points to the presence of mist, containing swollen aerosols. Interestingly, the Zurich sonde reveals a pronounced boundary layer inversion of $3-4^{\circ} \mathrm{C}$. At the ground the air was very moist, with $\mathrm{RH}_{\mathrm{liq}} \sim 100 \%$, i.e., at the onset of rain. Some of the problems with this sounding discussed below might be related to raindrops that might have collided with the housing of the SnowWhite sensor. This is different at Payerne, with $\mathrm{RH}_{\text {liq }} \sim 95 \%$.

The Payerne sounding shows a gap in backscatter between 9 and $10 \mathrm{~km}$ resulting in two separate cirrus layers, but when the air arrived over Zurich, the gap was filled. There are several possible explanations:

a. The gap might have been filled by ice crystals sedimenting from higher levels.

b. It might have been filled by new particle nucleation.

c. It may have been due to the presence of internal dynamics and instabilities (shallow convection) within the cloud.

d. Wind shear might have led to different air masses being transported into the gap layer.

Hypotheses (c) and (d) cannot be investigated by means of a trajectory column approach. In particular, we have no means to rule out (d), apart from the fact that the cloud gap and its filling is observed exactly at the best match altitude, rendering wind shear effects a questionable explanation. Hypothesis (c) may be investigated by inspection of stability along the two balloon tracks. Equivalent potential temperature is a good indicator for potentially unstable layers in an air column (Houze, 1993), which takes temperature changes in an air parcel resulting from potential latent heat release or consumption upon cloud particle condensation/evaporation into account. It is defined as $\theta_{\mathrm{eq}}=\theta \exp \left(L_{\mathrm{s}} q_{\mathrm{v}} / c_{\mathrm{p}} T\right)$, where $L_{\mathrm{s}}$ denotes the latent heat of sublimation, $q_{\mathrm{v}}$ is the mixing ratio of water vapor mass per mass of dry air, $c_{p}$ is the specific heat of dry air at constant pressure and $\theta=T \times\left(p_{0} / p\right)^{2 / 7}$ is the potential temperature with air temperature $T$ and pressure at the Earth's surface $p_{0}$. The stability criterion reads

$$
\frac{\partial \theta_{\mathrm{eq}}}{\partial z} \begin{cases}>0, & \text { potentially stable } \\ =0, & \text { potentially neutral } \\ <0, & \text { potentially unstable. }\end{cases}
$$

Figure 6 shows the equivalent potential temperature $\theta_{\text {eq }}$ derived from $p, T$ and $\mathrm{q}_{v}$ for both soundings. While a potential instability is present between 6.5 and $8 \mathrm{~km}$ over Payerne in the altitude layer supporting the supercooled liquid cloud, at cirrus levels the atmosphere is potentially stable or neutral. The same holds for the Zurich sounding, containing an unstable layer below $7 \mathrm{~km}$, as well as a shallow layer around $11 \mathrm{~km}$, which might potentially be unstable. This instability might indicate the presence of shallow convection inside cirrus clouds, as proposed and investigated by Spichtinger (2014). Overall, the Zurich profile suggests more dynamical activity on 100-200 m altitude scales, which may lead to vertical air mass exchange over this altitude range, but none of the profiles suggests convection to an extent that would prohibit a trajectory analysis.

Explanations (a) and (b) are investigated in the subsequent sections first by detailed comparison with COSMO data, then by comprehensive microphysical modeling, and finally by a discussion of the quality of the $\mathrm{RH}_{\text {ice }}$ data. Concerning the closure of the cloud gap between 9 and $10 \mathrm{~km}$ altitude, as can be seen below, the model provides evidence against extensive ice particle sedimentation (explanation a) but clearly supports new ice nucleation between Payerne and Zurich (explanation b).

\subsection{Comparison of COSMO-7 fields with measurements}

We intend to investigate the microphysical changes in the air mass traveling from Payerne towards the second launch location using a spectral (i.e., particle-size-resolving) column box model, driven by temperature and pressure fields from COSMO-7 analyses (the COSMO-2 domain is too small for this purpose). The trajectories have been calculated forward and backward from the flight track of the balloon launched from the MeteoSwiss station at Payerne, covering the altitude range of 5 to $12.6 \mathrm{~km}$ with $100 \mathrm{~m}$ vertical intervals. The starting point for the initialization of the box model was chosen $16 \mathrm{~h}$ upstream the Payerne sounding, beginning the simulation with cloud-free conditions at all trajectory levels. This avoids having to initialize the ice distribution, which cannot be extracted from the measurements.

Prior to the comprehensive microphysical modeling, we validate the accuracy of COSMO-7 analysis fields comparing temperature, humidity, ice and vapor mixing ratio profiles extracted along the balloon temperature profiles with the measured data. As can be seen below, COSMO-7 misjudges the timing of the warming by about half an hour, i.e., COSMO runs early. We therefore compared the observed and modeled data not only at the position of the balloon (green curves in 
Fig. 7) but also for a position half an hour upstream (black curves in Fig. 7). The temperature difference between the model value and measurement is presented in panels a and e of Fig. 7 for Payerne and Zurich, respectively. The altitude range of interest is between 400 and $180 \mathrm{hPa}$. COSMO temperatures are in excellent agreement with the Payerne sonde, but are $\sim 2 \mathrm{~K}$ warmer than the temperature measured by the Zurich sonde between 250 and $200 \mathrm{hPa}$. This is exactly where the upper part of the measured cirrus cloud was located. Water vapor mixing ratios of the model relative to the measurement over Zurich (Fig. 7f) appear $20 \%$ lower, which is also reflected in the $\mathrm{RH}_{\text {ice }}$ profile (Fig. $7 \mathrm{~g}$ ), whose upper part of the cloud is subsaturated in the model by almost $30 \%$. Correspondingly, the COSMO IWC (Fig. 7h) indicates no presence of an ice cloud at these altitudes; that is, the trajectories are too warm and too dry when they reach the Zurich region. This makes them poor candidates for driving the microphysical model in order to produce the measured high supersaturations. Another NWP caveat potentially contributing to the erroneous humidity representation is the one-moment bulk microphysics scheme implemented in COSMO, which is not able to capture the fine measured structure and prevents the persistence of ice supersaturation. Following a similar procedure as in Brabec et al. (2012) we compare COSMO IWC to the IWC estimated from the BSR measurements. To this end we assume the ice crystal mode radius $r_{\mathrm{m}}$ of in situ-formed cirrus clouds to lie in a typical range of 5 to $20 \mu \mathrm{m}$, yielding an overall uncertainty in the BSR of a factor of $\sim 4$. Over Payerne, the COSMO data suggest the existence of a single cloud layer with a maximum in IWC exactly where the gap between the two cloud layers is detected by the measurements (Fig. 7d). Over Zurich the lower part of the cloud is represented by COSMO data, overestimating IWC values by one order of magnitude compared to the measured values, whereas the uppermost part of the cloud is completely missed.

As a regional model, COSMO is designed to properly match the timing of cooling or heating. However, the current observations represent a case with poor matching of the onset of warming. Displacing the COSMO profiles to a position half an hour upstream of the balloon tracks slightly alleviates the discrepancy with the measurements (the profiles displaced by $30 \mathrm{~min}$ are shown as black curves in all panels of Fig. 7). Note that for clarity all quantities for the half an hour upstream position are calculated following the same COSMO trajectory, and plotting it at the pressure of the trajectory assumes at the balloon track (i.e., the black points in Fig. 7 are at the same $\theta$ as the corresponding green points; plotting the black points instead as a function of upstream temperature leaves all panels except for temperature basically unchanged, where the black curve becomes much more similar to the green curve because of the quasi-adiabatic layering of the tropospheric air).

The temperature difference between COSMO and measured data is $2 \mathrm{~K}$ at the upper cloud part. This explains the
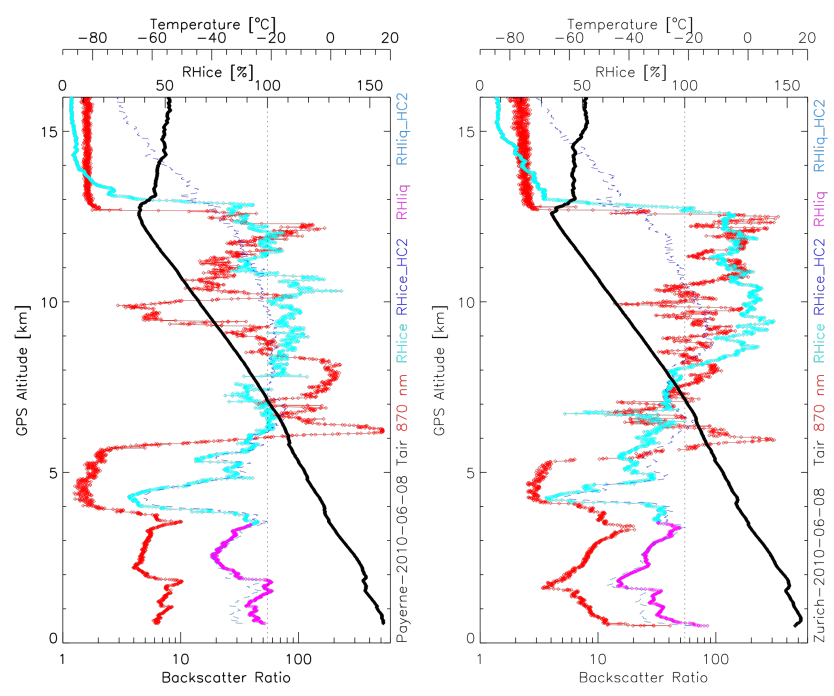

Figure 5. Soundings on 8 June 2010 launched from the MeteoSwiss station at Payerne at 20:04 UTC (left) and from a mobile launch platform that was driven to $47.45^{\circ} \mathrm{N}, 7.99^{\circ} \mathrm{E}$ (a location close to Frick, some $50 \mathrm{~km} \mathrm{WNW}$ of Zurich) at 21:28 UTC (right). Thick black line: temperature profile. Red: measured backscatter ratio at $870 \mathrm{~nm}$ wavelength. Cyan: $\mathrm{RH}_{\text {ice }}$ calculated from SnowWhite frost/dew point measurement by assuming solid condensate on the SnowWhite mirror above $7 \mathrm{~km}$ and liquid condensate below $7 \mathrm{~km}$. Magenta: $\mathrm{RH}_{\text {liq }}$ calculated from SnowWhite dew point measurement. Thin dashed dark- and light-blue lines: $\mathrm{RH}_{\text {ice }}$ and $\mathrm{RH}_{\text {liq }}$, respectively, measured by Rotronic HC2 capacitive polymer sensor. Note that the apparent supersaturation with respect to liquid water in the boundary layer suggested by SnowWhite is caused by partial evaporation of hydrometeors while they enter the heated instrument inlet (see text).

slight improvement in $\mathrm{RH}_{i c e}$ and also the survival of the cloud in the layers around $300 \mathrm{hPa}$. Half an hour upstream from Payerne, below $200 \mathrm{hPa}$, trajectories are still warmer and, correspondingly, the IWC is still lower.

\subsection{Microphysical analysis based on COSMO-7 trajectory fields including small-scale temperature fluctuations and other unknowns}

Microphysical analysis based on COSMO-7 trajectory fields without small-scale temperature fluctuations brought us to the following conclusions (see Appendix A): ZOMM manages to capture both BSR and $\mathrm{RH}_{\text {ice }}$ measured by the Payerne sonde very well, except for the highest cirrus between $11 \mathrm{~km}$ and the tropopause at $12.6 \mathrm{~km}$. Conversely, the model fails to reproduce the measurements by the Zurich sounding about $1.5 \mathrm{~h}$ downstream. This failure is partly due to a COSMO timing error, but even when this is corrected, ZOMM forced by the original COSMO meteorological fields cannot reproduce the observed supersaturation in a thick cirrus layer at $10-12 \mathrm{~km}$ altitude. 


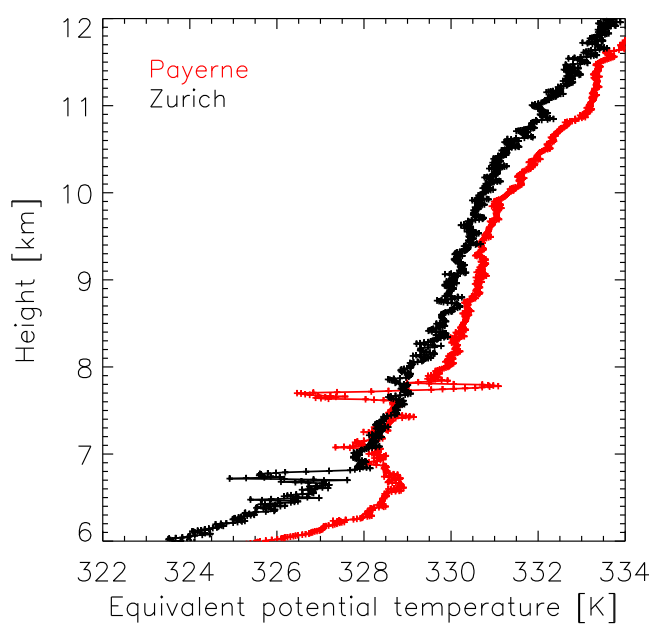

Figure 6. Equivalent potential temperature profile $\theta_{\mathrm{eq}}$ calculated from Payerne and Zurich soundings showing the presence of potentially unstable layers indicative of convective activity.

One known important reason for the model's inability to represent the more persistent cirrus layer in the upper part of the profile is its lack of small-scale temperature fluctuations, i.e., unresolved variations along the air mass trajectories, which affect cooling rates and therefore cause mostly higher ice crystal number densities, smaller radii, smaller sedimentation speeds and longer cirrus lifetime. Other unknowns are certain microphysical properties, e.g., of the mass accommodation coefficients, which may delay the sublimation of ice, or the presence of heterogeneous ice nucleation on a few preexisting ice nuclei. In what follows we use the match experiment data to discuss these model aspects.

\subsubsection{Small-scale temperature fluctuations}

In order to reproduce the unresolved small-scale temperature fluctuations $\left((\mathrm{d} T / \mathrm{d} t)_{\mathrm{ss}}\right)$, characteristic fluctuations were superimposed on the trajectories derived from the COSMO7 meteorological data. We refine a procedure that has been used for a similar purpose by Brabec et al. (2012). The fluctuation frequency spectrum was adopted again from Hoyle et al. (2005) based on the vertical wind and temperature measurements from the "Subsonic Aircraft: Contrail and Cloud Effects Special Study" (SUCCESS) campaign. The $(\mathrm{d} T / \mathrm{d} t)_{\mathrm{ss}}$ applied here were constructed from the SUCCESS data such that only wavelengths smaller than $30 \mathrm{~km}$ are retained. This cutoff wavelength is chosen because longer wavelength perturbations are already resolved by the $7 \mathrm{~km}$ grid spacing of COSMO-7. Concerning the proper choice of fluctuation amplitudes, three different scenarios were analyzed: clear-sky, cloudy-sky and - as a combination of both - "all-sky" conditions. This approach basically assumes a quasi-universal form of the spectral shape of gravity wave motions, whose amplitude can be scaled to reflect space and time differences. This is largely supported by considerable research activity in this area over the past two decades (Fritts and Alexander, 2003).

For the fluctuation amplitudes we follow the work by Gallice et al. (2011), who showed that information on air vertical motion can be derived from the ascent rate of sounding balloons. The deviation of the observed ascent of a sounding balloon from the one expected in vertically quiet air, as derived from a detailed treatment of the balloon motion taking internal heat flow and skin friction into account, is caused by the vertical motion of the air. Much simplified, but agreeing in general with this work, the vertical wind of air $(w)$ can be estimated from the original ascent data of the sounding balloons by subtracting a $500 \mathrm{~s}$ running mean (boxcar over 500 one-second GPS measurements), which represents approximately the ascent of the balloon in quiet air.

The $(\mathrm{d} T / \mathrm{d} t)_{\mathrm{ss}}$ can be readily calculated from $w$ : $(\mathrm{d} T / \mathrm{d} t)_{\mathrm{ss}}=-(\mathrm{d} T / \mathrm{d} z) \times w$, where $\mathrm{d} T / \mathrm{d} z$ is the adiabatic lapse rate $\left(\sim 10 \mathrm{~K} \mathrm{~km}^{-1}\right)$. The average cooling rate outside of clouds was determined from the GPS data recorded during 10 radiosonde ascents performed from Payerne and Zurich. An average cooling rate of $\left\langle(\mathrm{d} T / \mathrm{d} t)_{\mathrm{ss}}\right\rangle_{\text {clear }}=-12 \mathrm{Kh}^{-1}$ was obtained from these soundings (where $\langle\ldots\rangle$ is the arithmetic mean taken over all negative rates), comparing well with the mean $-11 \mathrm{~K} \mathrm{~h}^{-1}$ found in convectively unperturbed periods during SUCCESS (Hoyle et al., 2005). The average cooling rate in clouds extracted from the present two flights exhibits almost twice the cooling rate of the clear-sky scenario, $\left\langle(\mathrm{d} T / \mathrm{d} t)_{\text {ss }}\right\rangle_{\text {cloudy }}=-23 \mathrm{~K} \mathrm{~h}^{-1}$, which we attribute to small-scale cloud internal dynamics. Using the average clear and cloudy-sky fluctuations, we scale the SUCCESS data by adjusting the fluctuation amplitudes from Hoyle et al. (2005), and from this we obtain a mean fluctuation amplitude. The all-sky scenario superimposes cloudy-sky temperature fluctuations on those parts of the trajectories, where ZOMM determined clouds, and clear-sky temperature fluctuations on cloud-free parts. We use the ice number density threshold $n_{\text {ice }}>10 \mathrm{~L}^{-1}$ within ZOMM as a criterion to distinguish between these cases. In addition we require $\mathrm{RH}_{\text {ice }}<1.35$ as an indicator for the end of the homogeneous nucleation event and the beginning of the cloudy part with release of latent heat and subsequent small-scale turbulence.

Each of these three sets of small-scale fluctuation distributions was used as basis for an independent, comprehensive column model calculation in order to demonstrate the consequences of the fluctuations on the cirrus cloud properties. For each set, 10 randomly chosen fluctuation sequences (such as those shown by Hoyle et al. (2005) in their Fig. 2) were superimposed onto the COSMO trajectories. As a generic result, the application of any of the three fluctuations sets significantly improves the agreement with the sonde measurements by letting the clouds develop less pronounced fall streaks and survive to the Zurich sounding and beyond, with $n_{\text {ice }}$ enhanced by more than one order of magnitude compared to the scenario without fluctuations. Figures 8 and 9 show an example applying the fluctuations of the all-sky 

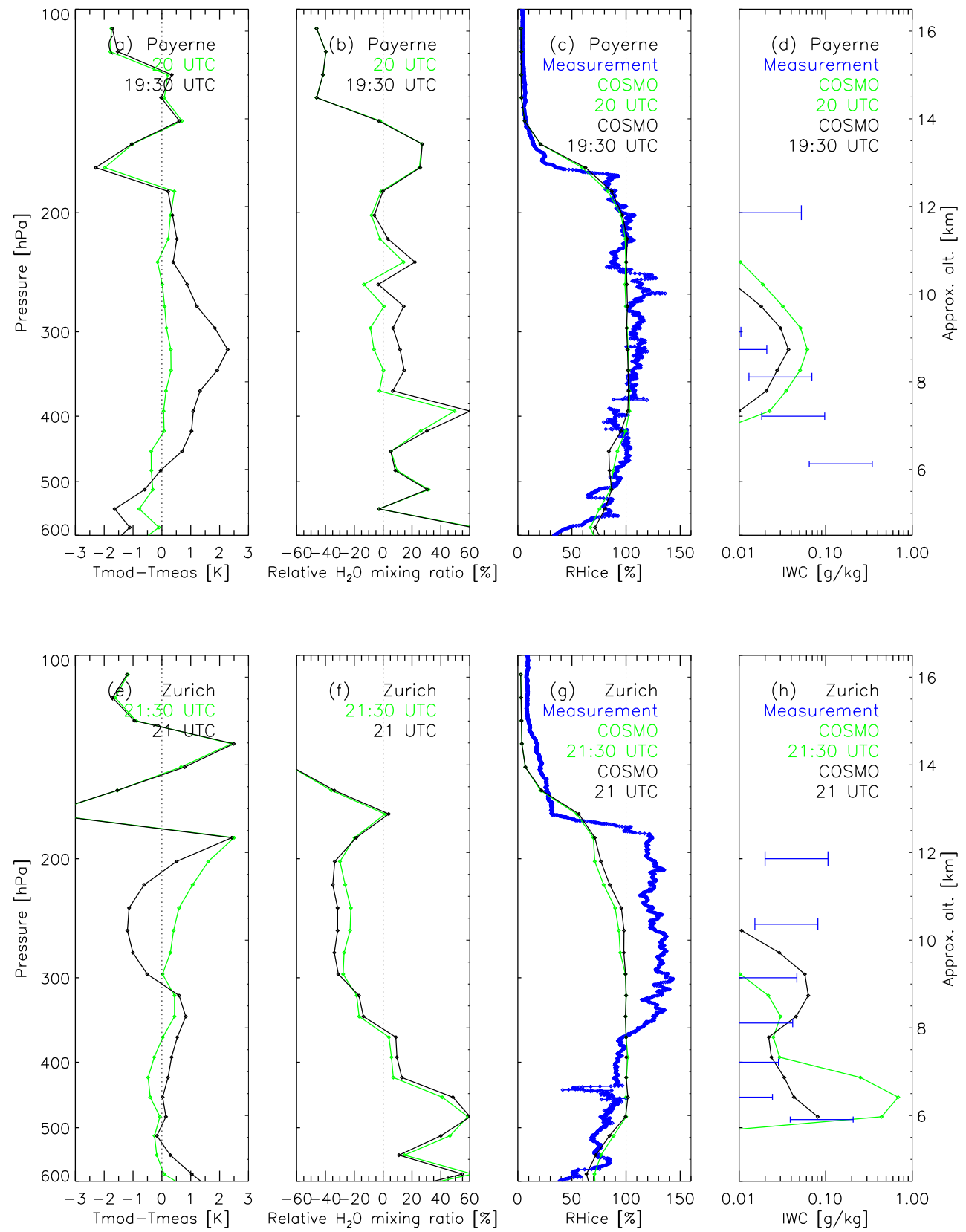

Figure 7. Validation of COSMO-7 analysis data with the sonde measurements over Payerne (upper row) and Zurich (lower row) along the balloon track (green points) or half an hour upstream (black points): (a) and (e) temperature difference between COSMO and measured data; (b) and (f) percentage difference between model and measurement in water mixing ratio $\left(\chi_{\mathrm{w}, \text { mod }}-\chi_{\mathrm{w}}\right.$ meas $) / \chi_{\mathrm{w}, \text { meas }}$; (c) and (g) relative humidity with respect to ice $\mathrm{RH}_{\mathrm{ice}}$ obtained from the measurement data (blue) and COSMO data (black and green); (d) and (h) same for the ice water content (IWC), with blue bars showing uncertainty range in IWC estimated from the COBALD data.

scenario. These fluctuations have a much greater impact on cirrus properties than do the differences between the three fluctuation types.

As a metric to objectify the quality of the match between the model results and the measurements we introduce the quantity

$M=\int_{9 \mathrm{~km}}^{12.5 \mathrm{~km}} \mathrm{~d} z \ln \mathrm{BSR}_{\mathrm{mod}} / \int_{9 \mathrm{~km}}^{12.5 \mathrm{~km}} \mathrm{~d} z \ln \mathrm{BSR}_{\text {meas }}-1$.

This metric uses the backscatter ratio, because it integrates all cloud processes over a wide range of meteorological 
Table 2. Relative error (in \%) given by $M$ in Eq. (3) between backscatter measurement and model results for the run with the best fluctuation member using the clear, cloudy or "all sky" scenarios. Microphysical conditions are unity mass accommodation coefficient $(\alpha=1)$ and the absence of ice nuclei $\left(n_{\mathrm{IN}}=0\right)$.

\begin{tabular}{lrrrr}
\hline & COSMO & \multicolumn{3}{c}{ COSMO with superimposed fluct. } \\
& without fluct. & clear sky & cloudy sky & "all sky" \\
\hline Payerne & -51 & -15 & 0 & -21 \\
Zurich & -76 & -17 & -9 & -31 \\
\hline
\end{tabular}

conditions upstream of the measurement. It is therefore largely independent of the instantaneous temperature fluctuation at the location and time of the measurement. In contrast, relative humidity depends strongly on the temperature in the moment of the measurement and hence is not considered to be suited for judging the quality of the cloud modeling. The logarithmic form of Eq. (3) ensures that not only the largest BSR enter the evaluation.

Graphically, Eq. (3) is the relative area between the model curves and the measurements in Fig. A3a, e or 9a, g (with a lower limit taken at the upper edge of the liquid cloud). The metric only accounts for deviations in mean values, not for the mean squared error, in order to exclude altitude errors, which would more likely be an error of the underlying meteorological model than of the microphysical treatment. Therefore, in Fig. 9a, the cloud gap above Payerne is modeled at an altitude that is too low by about $1 \mathrm{~km}$, and the metric does not punish this fact.

Table 2 lists the results for $M$ (in \%) for the scenario without fluctuations and with superimposed clear, cloudy and allsky fluctuations. In order to obtain the information in Table 2, $M$ was calculated independently for each of the 10 fluctuation runs in each scenario, and the run agreeing best with the Payerne and Zurich measurements is listed (evaluated at the position half an hour upstream). The scatter in $M$ between different fluctuations is substantial: for example, the scenario for clear-sky conditions at Payerne with $M=-15 \%$ may for other fluctuations be as bad as $M=-62 \%$. Once again, this illustrates the sensitivity of the cloud results to fluctuation events that might have happened far upstream.

Clearly, the major improvement over the scenario using the COSMO trajectories only (left column in Table 2) is the introduction of fluctuations, while the differences between the particular types of fluctuations (for the run with the best fluctuation member) are less important. Here, the parameterization using the cloudy-sky conditions yields the best agreement with the observations. However, it can be seen below that microphysical uncertainties are in the same range as the differences between the various fluctuation scenarios. Therefore, different microphysical assumptions may make other fluctuation scenarios more favorable.

There is an ambiguity regarding how to superimpose the $(\mathrm{d} T / \mathrm{d} t)_{\mathrm{ss}}$ fluctuations onto the COSMO-based trajectories concerning their phase relation within the air column. The two extremes are either a completely random application (i.e., each trajectory has a different sequence of $\left.(\mathrm{d} T / \mathrm{d} t)_{\mathrm{ss}}\right)$ or fluctuations are in phase for all altitudes. The real atmosphere is somewhere in between. In this work we apply fluctuations in phase for all altitudes. We will return to this matter in Sect. 4.4.4.

In passing we note that we also investigated the impact of latent heat release on the trajectory temperatures, which might differ between the microphysics schemes in COSMO and in ZOMM. We performed full ZOMM column calculations based either on the diabatic COSMO 3-D trajectories (which include latent heat and radiative effects) or on adiabatic trajectories using only the COSMO pressure as input and correcting for the latent heat release within ZOMM itself. Results are slightly better with the adiabatic trajectory approach, but the differences are not significant. Figure 8 and subsequent figures therefore show results from the adiabatic approach.

Figure 9 shows the comparison between the measured BSR and $\mathrm{RH}_{\text {ice }}$ over Zurich and Payerne and the profiles taken from Fig. 8 at the 30 min upstream position (i.e., black balloon track in Fig. 8). Black lines in Fig. 9 show the single model member with the fluctuations that agree best with the observation in terms of $M$ (i.e., the computation using same member, fluctuation no. 6 , evaluated at both positions), while the grey shaded area shows the results for all 10 ensemble members with the randomly chosen fluctuations.

Comparing the BSR profiles at both locations we conclude that the cloud gap around $320 \mathrm{hPa}$ is filled up on the way between Payerne and Zurich, either due to formation of new particles or by sedimentation from the levels above, with modeled BSR and number densities of the ice crystals increasing by about one order of magnitude. This cloud gap above Payerne is also clearly visible in all panels of Fig. 8, which basically verifies the quality of the COSMO-7 temperature fields, enabling ZOMM to model this gap. The model succeeds in filling this cloud gap (compare black curves in Fig. 9a and Fig. 9g). From Fig. 8a it is clear that the air cooled between Payerne and Zurich to reach conditions of homogeneous nucleation, and the stepwise increase in $n_{\text {ice }}$ and BSR in Fig. $8 \mathrm{~b}$ and d shows that the gap was filled by a new nucleation event in the midst of clouds. However, from the grey ensemble area in Fig. 9g it is also clear that not every ensemble member is performing this task; that is, the exact choice of ensemble member plays a big role in achieving agreement with the measurement. This highlights once again the importance of small-scale temperature fluctuations $(\mathrm{d} T / \mathrm{d} t)_{\mathrm{ss}}$ and our limited ability to provide a deterministic picture. Rather, we have to rely on probabilistic analysis, similar to weather forecasts, where weather services have also begun to make full use of ensemble member analysis. 

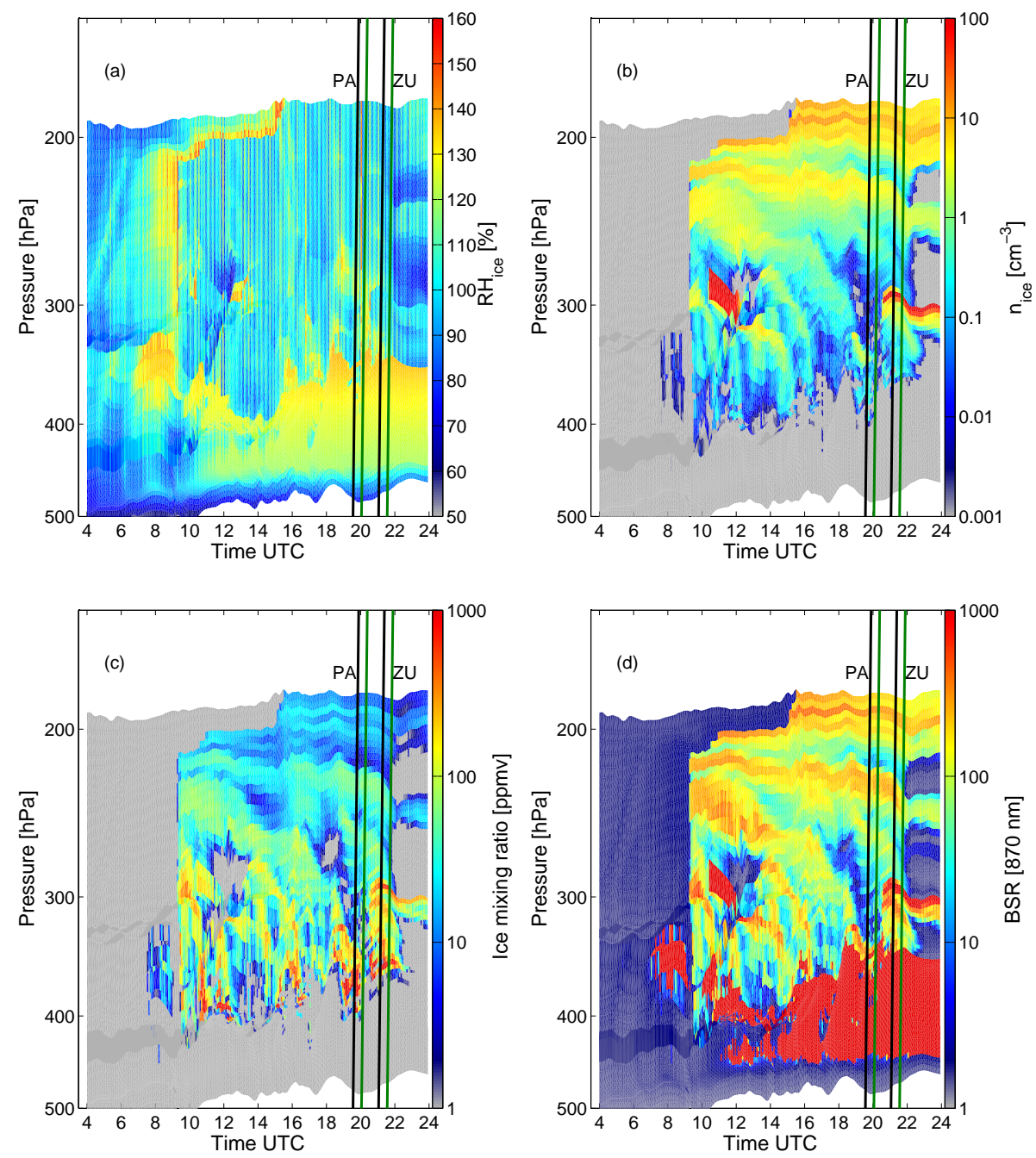

Figure 8. Detailed microphysics runs with column spectral model based on the original COSMO-7 analysis fields with superimposed smallscale temperature fluctuations: (a) Relative humidity with respect to ice, (b) ice crystal number density, (c) ice mixing ratio (defined as number of water molecules condensed in ice per number of air molecules) and (d) aerosol backscatter ratio ( $870 \mathrm{~nm}$ wavelength). Green lines: flight tracks of balloons launched from Payerne ("PA") and Zurich ("ZU"). Black lines: positions shifted by half an hour upstream (to compensate for a COSMO warming time error). Thin vertical stripes in $\mathrm{RH}_{\mathrm{ice}}$ reveal the $(\mathrm{d} T / \mathrm{d} t)_{\mathrm{ss}}$ superimposed on the adiabatic trajectories based on COSMO fields. All-sky conditions are assumed for the small-scale temperature fluctuations, mass accommodation coefficient of $\mathrm{H}_{2} \mathrm{O}$ on ice is a function of $\mathrm{RH}$ and no heterogeneous nucleation is assumed (see text).

\subsubsection{Mass accommodation of $\mathrm{H}_{2} \mathrm{O}$ on ice}

Aside from meteorological processes on the small scale (e.g., $\left.(\mathrm{d} T / \mathrm{d} t)_{\mathrm{ss}}\right)$, which force the microphysics of cirrus, there are other independent microphysical aspects which affect cirrus properties. At low temperatures, clean ice is thought not to develop a quasi-liquid surface layer; rather, the water molecules need to be accommodated directly on the crystalline ice surface. Accommodation is impeded, even when $\mathrm{RH}_{\text {ice }}>100 \%$, because molecules need to arrive at a suitable position on the surface and in the right orientation or else they will be either reflected back into the gas phase or adsorbed only loosely and subject to rapid desorption.
This impedance has been ascribed to conditions when the outermost lattice monolayer is complete and a new monolayer needs to start via "surface nucleation". In analogy, $\mathrm{H}_{2} \mathrm{O}$ molecules do not evaporate at $\mathrm{RH}_{\text {ice }}<100 \%$ without impedance: when the outermost lattice monolayer has completely evaporated, defects need to "nucleate" first in order to facilitate further evaporation. These processes are traditionally quantified by a mass accommodation coefficient $(\alpha \leq 1)$, which comprises all details of the surface processes and describes the probability of $\mathrm{H}_{2} \mathrm{O}$ molecules condensing to/evaporating from an ice surface compared with the absence of the surface impedance. Surface impedance has been discussed as a potential mechanism to explain high 

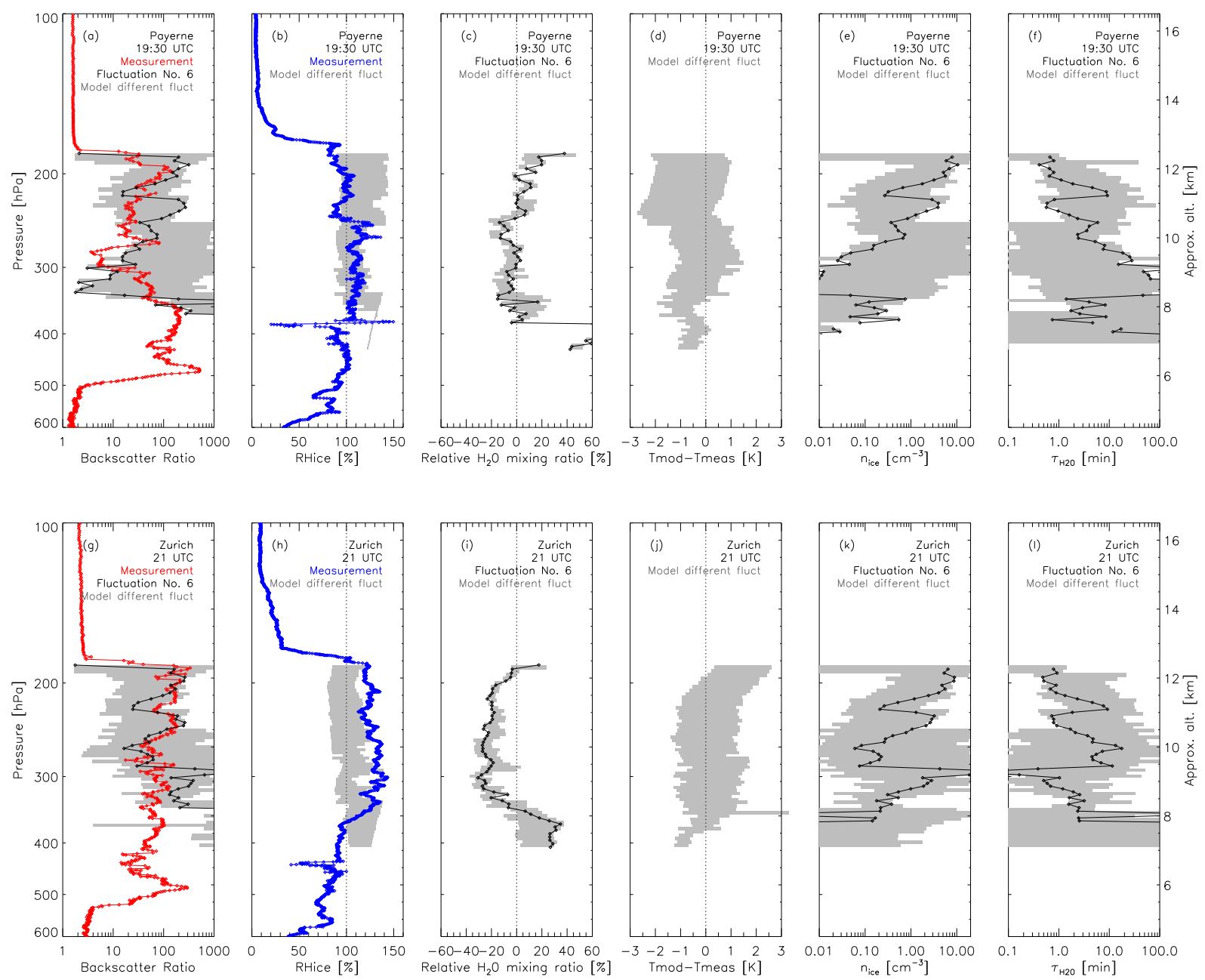

Figure 9. Comparison of sonde measurements of BSR at $870 \mathrm{~nm}\left(\mathbf{a}, \mathbf{g}\right.$, red lines), $\mathrm{RH}_{\mathrm{ice}}$ (b, h, blue lines), relative $\mathrm{H}_{2} \mathrm{O}$ mixing ratio (c, $\mathbf{i})$, difference in temperature between model and measurement $(\mathbf{d}, \mathbf{j})$, ice crystal number density $(\mathbf{e}, \mathbf{k})$, and equilibrium time for gas-phase depletion on ice particles (f, l) in Payerne (upper row) and Zurich (lower row) with the model results based on COSMO-7 trajectories with superimposed small-scale temperature fluctuations (all-sky scenario). Black lines: best fluctuation member. Grey shaded areas: results for all 10 ensemble members with randomly chosen fluctuations. Comparison is made half an hour upstream of the exact measurement time using adiabatic trajectories with latent heat corrections from ZOMM (see Sect. 4.4.1), and $\alpha=f\left(\mathrm{RH}_{\mathrm{ice}}\right)$ (see Sect. 4.4.2), but no heterogeneous nucleation.

and persistent in-cloud supersaturations (Peter et al., 2006, 2008). The similarity of these processes with nucleation explains why $\alpha$ is likely a function of supersaturation, i.e., $\alpha=f\left(\mathrm{RH}_{\text {ice }}\right.$ ) (see, for example, MacKenzie and Haynes (1992) or Wood et al. (2001)). We follow these ideas of an RH-dependent mass accommodation coefficient of $\mathrm{H}_{2} \mathrm{O}$ molecules on ice and compare with the results for $\alpha=1$. Details for the derivation of $\alpha=f\left(\mathrm{RH}_{\text {ice }}\right)$ are given in Appendix B.

Despite the fact that our approach here assumes $\alpha$ to deviate considerably from values around unity, the consequences for the modeled BSR of the Payerne and Zurich soundings are moderate, as the results in Table 3 show. The calculations for Table 3 are similar to Table 2, only that $\alpha=1$ has been re- placed by $\alpha=f(\mathrm{RH})$. Compared to Table 2 , the reduction in $\alpha$ leads to reduced sensitivity of the ice particles compared to evaporation in the warming time and thus to a general increase of BSR, and thus $M$ in Table 3. The all-sky scenario listed in Table 3 is identical to Fig. 9a and g.

\subsubsection{Heterogeneous nucleation of ice}

Finally, we investigated how the existence of a small number of heterogeneous ice nuclei influences the cirrus formation, and whether the expected effects improve the modelmeasurement agreement. A new study by Cziczo et al. (2013) shows from observations in midlatitude cirrus in the United States that heterogeneous freezing dominated the formation of cirrus, at least in the field campaigns investigated in 
Table 3. Relative error (in percent) given by $M$ in Eq. (3) between backscatter measurement and model results for the runs with the best fluctuation member with mass accommodation coefficient $\alpha=f(\mathrm{RH})$ and the scenarios for clear, cloudy or all sky. Model runs assume the absence of ice nuclei $\left(n_{\mathrm{IN}}=0\right)$. The rightmost column corresponds to the scenario shown in Fig. 9a and g.

\begin{tabular}{lrrrr}
\hline & $\begin{array}{r}\text { COSMO } \\
\text { without fluct. }\end{array}$ & \multicolumn{4}{c}{ COSMO with superimposed fluct. } \\
clear sky & cloudy sky & all sky \\
\hline Payerne & -51 & +8 & +8 & +5 \\
Zurich & -76 & -7 & -8 & +2 \\
\hline
\end{tabular}

this study. ZOMM has been used previously for heterogeneous ice nucleation in the immersion mode (see Engel et al. (2013)) and we closely follow their treatment. For technical details, see Appendix C.

We follow Marcolli et al. (2007) and describe the nucleation process using active site theory. The mean area of an active site is assumed to be $A_{\text {as }}=10 \mathrm{~nm}^{2}$. Even though a single particle may have several active sites, the best active site with the smallest contact angle $\gamma$ is dominant, and this one is treated by the model. The occurrence probability of active sites decreases with decreasing $\gamma$, i.e., the better the site, the rarer it is. The number density of foreign nuclei (e.g., mineral dust), containing at least one active site with a minimum contact angle $\gamma$ (i.e., the number of foreign nuclei in one particular contact angle bin), is then given by

$n_{\gamma}=\left(n_{\text {foreign }}-\sum_{\gamma^{\prime}-47^{\circ}}^{\gamma-1^{\circ}} n_{\gamma}^{\prime}\right) \times P_{\mathrm{as}}(\gamma) \times \frac{4 \pi r_{\text {foreign }}^{2}}{A_{1}}$,

from which we obtain an equivalent volume-based nucleation rate of

$J_{\mathrm{vol}}(T)=\sum_{\gamma=47^{\circ}}^{180^{\circ}} n_{\gamma} \times J_{\text {het }}(T, \gamma) \times A_{1}$.

The only unknown in this formulation is $n_{\text {foreign }}$, the overall number density of heterogeneous ice nuclei. Here we adopted the canonical value of $10 \mathrm{~L}^{-1}$ by DeMott et al. (2003). Table 4 lists two heterogeneous scenarios in comparison with other scenarios, while Table $\mathrm{C} 1$ shows additional calculations for various IN concentrations (see Appendix C). There we show that the agreement with measurements worsens for increasing $n_{\mathrm{IN}}$.

\subsubsection{Comparison of cirrus formation mechanisms}

In the preceding subsections we summarized a number of mechanisms possibly involved in the formation and maintenance of the cirrus clouds observed in the match flights from Payerne and Zurich on 8 June 2010:

1. homogeneous ice nucleation supported by small-scale temperature fluctuations $(\mathrm{d} T / \mathrm{d} t)_{\mathrm{ss}}$;
2. impeded particle growth/evaporation, e.g., the humidity-dependent mass accommodation $\alpha=f(\mathrm{RH})$ $\ll 1$;

3. heterogeneous nucleation on a few potent ice nuclei (e.g., $n_{\mathrm{IN}}=10 \mathrm{~L}^{-1}$ ).

In addition to these major processes we also investigated the effect of using either diabatic or adiabatic trajectories (latent heat-corrected), which has a minor impact on the modeled clouds. A total of 264 column model calculations have been performed for the following scenarios: (clear or cloudy or all sky) $\times$ (diabatic or adiabatic) $\times(\alpha=1$ or $f(\mathrm{RH})) \times\left(n_{\mathrm{IN}}=0\right.$ or $\left.10 \mathrm{~L}^{-1}\right)=3 \times 2 \times 2 \times 2=24$ scenarios and for each of these scenarios applying 10 random fluctuation distributions plus one without fluctuations.

In addition to comparing with the "best" fluctuation member we also calculated the median and mean values of all 10 trajectories in a scenario for each altitude (not shown). As mentioned in Sect. 4.4.1, we applied fluctuations $(\mathrm{d} T / \mathrm{d} t)_{\mathrm{ss}}$ with the same phase for all altitudes. While this procedure is simple, it exaggerates the vertical dynamical coupling within an air column. We have not tried to apply a more realistic approach in our calculations, but using median or mean helps to avoid outliers at certain altitudes which, even though possible, are not very likely. The conclusions drawn from median and mean results do not differ much from the results shown in Tables 2-4, and are therefore not shown. In comparison with the single fluctuation results, median and mean results are smoother. Besides this advantage, showing the median instead of a single fluctuation case may also have drawbacks, as a comparison between the median results and second and third columns in Table 4 reveals: while the single case manages to develop the cloud gap (albeit at slightly too low altitude), the median does not. This comparison again highlights the care that needs to be taken when interpreting results from an ensemble calculation: the exact nature of $(\mathrm{d} T / \mathrm{d} t)_{\mathrm{ss}}$ in shaping the resulting cloud field is essential, highlighting the requirement of taking a probabilistic approach and then average, but a single member may be the best description of reality.

The synopsis of Tables 2-4 listing the metric $M=\int \mathrm{d} z \ln$ $\mathrm{BSR}_{\text {mod }} / \int \mathrm{d} z \ln \mathrm{BSR}_{\text {meas }}-1$ (see Eq. 3) allows for assessment of the ability of the various scenarios to represent the observed backscatter ratios (BSR). The major conclusions are as follows:

1. The introduction of small-scale temperature fluctuations $(\mathrm{d} T / \mathrm{d} t)_{\mathrm{ss}}$ is the dominant factor in reaching better compliance of the cloud model with the observations improving the cloud modeling beyond using trajectories directly from the regional weather forecast model COSMO-7 (compare first column of Table 2 with other columns of the same table).

2. A further moderate improvement can be achieved with additional microphysical assumptions such as assuming 
Table 4. Relative error (in percent) given by $M$ in Eq. (3) between backscatter measurement and model results for the runs with the best fluctuation member for the all-sky scenario. Two values of the mass accommodation coefficient $(\alpha=1$ and $f(\mathrm{RH}))$ and two values for heterogeneous ice nuclei $\left(n_{\mathrm{IN}}=0\right.$ and $\left.10 \mathrm{~L}^{-1}\right)$ are indicated.

\begin{tabular}{lrrrrr}
\hline & COSMO & \multicolumn{4}{c}{ COSMO with superimposed all-sky fluctuations } \\
& without fluct. & $\alpha=1$ & $\alpha=f(\mathrm{RH})$ & $\alpha=1$ & $\alpha=f(\mathrm{RH})$ \\
& $\alpha=1, \mathrm{IN}=0$ & $\mathrm{IN}=0$ & $\mathrm{IN}=0$ & $\mathrm{IN}=10 \mathrm{~L}^{-1}$ & $\mathrm{IN}=10 \mathrm{~L}^{-1}$ \\
\hline Payerne & -51 & -21 & +5 & +1 & -12 \\
Zurich & -76 & -31 & +2 & -8 & -8 \\
\hline
\end{tabular}

a surface impedance limiting the growth/evaporation of the ice particles $(\alpha=f(\mathrm{RH}) \ll 1$; see Table 3$)$ or the presence of heterogeneous nucleation on a few potent ice nuclei $\left(n_{\mathrm{IN}}=10 \mathrm{~L}^{-1}\right.$; see last two columns of Table 4). A combination of these effects did not lead to a further improvement.

3. Changes induced by the microphysical assumptions are of the same magnitude as changes induced by different assumptions for $(\mathrm{d} T / \mathrm{d} t)_{\mathrm{ss}}$, e.g., when using cloudy instead all-sky conditions (compare last two columns of Tables 2 and 3).

Moreover, introducing $\alpha=f(\mathrm{RH}) \ll 1$ and/or heterogeneous nucleation on a few potent ice nuclei $n_{\mathrm{IN}}=10 \mathrm{~L}^{-1}$ without implementing small-scale temperature fluctuations does not lead to any significant improvement in the simulation of BSR (not shown). Even though both small $\alpha$ and finite $n_{\mathrm{IN}}$ may lead to enhancements of $\mathrm{RH}_{\text {ice }}$ in the nucleation process of the cirrus clouds, these effects are too weak to cause a significant improvement (and assuming the presence of ice nuclei leads to even a slightly larger mismatch).

These conclusions are also not changed by the uncertainty in the ice particle shape (aspect ratio), which may lead to at most a change by a factor of 2 in BSR (see Sect. 3.5). That the factor of 2 does not represent a large change is visually clear from Fig. 9a and g, where a factor of 2 results in a minor shift of the black lines. We have recalculated Table 4 for these conditions and find the above conclusions to be confirmed. Specifically, for $\mathrm{BSR}_{\text {mod }} \longrightarrow 0.5 \times \mathrm{BSR}_{\text {mod }}$ the introduction of fluctuations continues to be the leading factor and microphysical details may possibly lead to some further improvement. For $\mathrm{BSR}_{\text {mod }} \longrightarrow 2 \times \mathrm{BSR}_{\text {mod }}$ the introduction of fluctuations already leads to a very good agreement with the measurements, and then changes in $\alpha$ or $n_{\mathrm{IN}}$ only worsen the result.

\subsubsection{Comparison of measured and modeled relative humidity}

So far we have not paid much attention to the modeled $\mathrm{RH}_{\text {ice }}$. As mentioned above, different from backscatter, $\mathrm{RH}_{\text {ice }}$ is directly sensitive to the $(\mathrm{d} T / \mathrm{d} t)_{\mathrm{ss}}$ at the position of the measurement. However, it is worth noting that the model yields reasonable agreement with $\mathrm{RH}_{\text {ice }}$ for the Payerne sounding (see Figs. A3b and 9b) but fails to explain the supersaturation measured by the Zurich sonde (see Figs. A3f and 9h). We refrain from showing the full spectrum of the results all the other model runs because they are all similar to Fig. 9b and $\mathrm{h}$. Hence, the inability of the model to reproduce the supersaturations observed above Zurich does not depend on the particular choice of fluctuation or microphysical scenario.

Figure 9 also shows ice crystal number densities, $n_{\text {ice }}$ (panels e and $\mathrm{k}$ ), and equilibration times, $\tau_{\mathrm{H}_{2} \mathrm{O}}$, for supersaturations inside cirrus clouds needed to relax due to uptake of water vapor by the ice particles (panels f, 1). The equilibration time is approximated as

$\tau_{\mathrm{H} 20}=\frac{1}{4 \pi D^{*} r n_{\mathrm{ice}}}$,

where $r$ and $n_{\text {ice }}$ are the mean particle radius and the number density of ice crystal inside a cloud, respectively. Furthermore, $D^{*}$ is the effective $\mathrm{H}_{2} \mathrm{O}$ gas-phase diffusion constant, which takes the $\mathrm{H}_{2} \mathrm{O}$ mass accommodation impedance into account. The correlations between $n_{\text {ice }}$ and BSR are apparent, as is the inverse dependence of $\tau_{\mathrm{H}_{2} \mathrm{O}}$. While $n_{\text {ice }}$ is sufficiently low above Payerne to have equilibration times $\tau_{\mathrm{H}_{2} \mathrm{O}}>1 \mathrm{~h}$, number densities above Zurich stay higher than $0.1 \mathrm{~cm}^{-3}$, resulting in $\tau_{\mathrm{H}_{2} \mathrm{O}}=1-10 \mathrm{~min}$. This renders the supersaturated conditions with $\mathrm{RH}_{\text {ice }}>120 \%$ over an altitude range of $\sim 4 \mathrm{~km}$, as observed by SnowWhite on that day, very unlikely.

The supersaturation observed by the Zurich sonde is perplexing also in view of the fact that the air masses are exposed to a general warming phase. The Meteosat cloud images confirm the evaporation of clouds, and the COSMObased trajectories in Fig. A1 also suggest a warming by about $2 \mathrm{~K}$ in the upper part of the cirrus cloud, which starts about $1 \mathrm{~h}$ before the air arrives over Zurich. Under these circumstances a slight subsaturation is expected, but not a supersaturation.

Two explanations remain possible: either there is an unknown mechanism, e.g., a surface impedance being as high as observed by Magee et al. (2006), with mass accommodation coefficients $\alpha \leq 10^{-4}$, which hinders the water from being absorbed and bound by the ice particles present in the same volume, or there could be an error in the SnowWhite measurement. Laboratory experiments have shown $\alpha<0.1$ 
(Pratte et al., 2006; Magee et al., 2006), which has been interpreted as colliding water molecules being trapped in a precursor state (Sadtchenko et al., 2004) on the ice surface and desorbing before being incorporated into the lattice. This inability of the surface to bind the water molecules has been related to surface disorder, which begins to develop on the topmost layers of ice at temperatures above $180 \mathrm{~K}$, and thus ice surfaces are potentially disordered under all conditions prevailing atmospheric conditions. However, the effect of this surface disorder on the water accommodation is not currently known (Bartels-Rausch et al., 2012). Nonetheless, surface impedances corresponding to mass accommodation coefficients $\alpha \leq 10^{-4}$ should have been detected in the laboratory, because under such extreme conditions, the uptake even by macroscopic ice surfaces $(r \sim 1 \mathrm{~mm})$ starts to display more than a doubling of characteristic uptake times. Moreover, very recently the accommodation coefficient was reported to be $>0.1$ at temperatures between 190 and $235 \mathrm{~K}$ (Skrotzki, 2012), which fully covers the cirrus clouds discussed here, and it is speculated whether some of the water vapor in the experiments by Magee et al. (2006) might possibly have deposited on the walls of the measurement cell.

In order to test the impact of very low $\alpha$, we ran one case with $\alpha=10^{-4}$. Interestingly, this run does not show any improvement in $\mathrm{RH}_{\text {ice }}$ over Zurich (except in the uppermost $500 \mathrm{~m}$ of the cloud). The reason is a subtle compensation for effects: while $\alpha=10^{-4}$ impedes the uptake of $\mathrm{H}_{2} \mathrm{O}$ from the gas phase, this leads to the formation of higher ice crystal number densities during the process of new particle nucleation. This, in turn, enhances the ice surface area density, which in terms of uptake kinetics largely compensates for the reduced mass accommodation coefficient.

\subsubsection{Potential error in SnowWhite measurement}

The alternative explanation is that the SnowWhite measurement of the Zurich sonde is erroneous. We consider this second explanation by far more likely. Either there could be an error in the SnowWhite frost point measurement corresponding to a water vapor mixing ratio $15-30 \%$ too high or the sensor measuring the ambient temperature caused an error of $1-2 \mathrm{~K}$ (because the vapor pressure of ice changes by $\sim 15 \%$ per degree temperature change). Both the frost point mirror and the air temperature are measured using a copperconstantan thermocouple (manufactured by Meteolabor) and the measurement uncertainty (one-standard-deviation error) for the temperature sensors is $\pm 0.2 \mathrm{~K}$ according to the manufacturer. The temperature difference between the two sensors is even more precise as the sonde internal temperature reference is the same for both. Fortunately, there is a second independent constantan-copper thermocouple measuring temperature, whose purpose is to correct the Rotronic HC2 humidity sensor located close to it inside the Styrofoam flow channel. We compared the temperature measure by the main sensor with that of the additional sensor and found both sensors to agree within $\pm 0.1 \mathrm{~K}$ all the way from the ground to the tropopause. As it would be a very unlikely coincidence that both sensors had the same calibration error, the hypothesis of a wrong temperature measurement can be abandoned. It is much more likely that there is a problem in the water vapor measurement. We know that the conditions on 8 June 2010 were adverse, because the sonde had to transit a $2 \mathrm{~km}$ thick mixed-phase cloud before reaching the cirrus level and because of the slightly rainy ground conditions. The latter is supported by the measurements of both SnowWhite and Rotronic HC2, showing $\mathrm{RH}<100 \%$ in Payerne and $\mathrm{RH}>100 \%$ in Zurich.

The following is speculative, but very likely: the Snow White inlet has a baffle, which is intended to keep stray light and hydrometeors away from the chilled mirror. However, if a supercooled precipitation drop falling out of the mixed-phase cloud were to hit the baffle, it would immediately freeze. The housekeeping data of the sonde show that the housing of the instrument (and hence the baffle) during that particular flight was $4 \mathrm{~K}$ warmer than ambient in the altitude range $8-15 \mathrm{~km}$. This occurred because the housing is heated by the warm side of the Peltier element, and even more so by an resistive heating, which switches on under conditions of supersaturation in order to avoid condensation within the flume. The assumed ice particle would then evaporate slowly and moisten the incoming air flow. Assuming that the ambient gas phase is in equilibrium with ice and the apparent supersaturation of $30 \%$ is due to evaporation of a frozen droplet on the baffle, we estimate from a simple mass balance that the droplet size is on the order of $1 \mathrm{~mm}$ in order to supply the air stream with $\Delta \mathrm{RH}_{\mathrm{ice}}=+30 \%$ for the whole time needed to traverse the cirrus layer. A phenomenon that might be taken as an argument against this explanation is that Snow White does show a steep gradient when passing from the troposphere into the stratosphere (Fig. 5b), as it would be a strange coincidence if the frozen droplet were to evaporate exactly at the tropopause. However, at the tropopause the controller switches the resistive heating off (the housekeeping data even show that the housing becomes colder than ambient), and therefore the forced evaporation of the frozen droplet becomes suppressed at the same moment ambient conditions become dry. Alternatively, as low as the boundary layer a rain drop (several millimeters in size) may have collided with the baffle, slowly evaporating all the way to the tropopause. Ground conditions were dry in Payerne, so this may explain the difference between both stations.

Although we do not know the exact details of what actually happened, this explanation is unfortunately very likely. This finding is significant and questions the accuracy of this and all similar humidity measurements. It calls for in-flight checks or calibrations of hygrometers under the special humidity conditions in the upper troposphere or at least for critical design reviews to avoid contamination (such as investigating the reliability of the chilled-mirror temperature 
measurement or the requirement that baffles prevent air from flowing straight through the region housing the mirror).

\section{Conclusions}

The occurrence of cirrus clouds and dehydration by sedimenting ice particles determines the water vapor budget and the radiative balance in the upper troposphere. To improve our understanding of the time evolution and life cycle of cirrus clouds in midlatitudes, we introduce a cloud-tracing or "match" technique. A Lagrangian measurement with one fixed and one mobile radiosonde station, supported by a comprehensive microphysical modeling approach, enables us to analyze changes in an air mass occurring within $1-3 \mathrm{~h}$ in particle backscatter and relative humidity with respect to ice. This allows for the occurrence and evolution of ice supersaturation inside and around midlatitude cirrus to be determined. Here we present the first results of match flights performed on 8 June 2010 over Switzerland. A comparison of measured and modeled values reveals the following:

1. The underlying regional weather forecast data from the COSMO-7 model show a timing error in a warming by about $30 \mathrm{~min}$, which needs to be corrected in order to understand the cloud measurements.

2. Even with the correction of the warming time error, the trajectories derived directly from the COSMO-7 wind fields are not suited for the cloud modeling, but underestimate the logarithm of the observed cirrus backscatter by $50-80 \%$.

3. The cloud modeling is not significantly improved by only changing the microphysical parameters of the clouds (such as surface impedance).

4. Rather, the superposition of small-scale temperature fluctuations not resolved by COSMO-7 is required to improve the model (such that it represents the logarithm of the observed cirrus backscatter to within 10-30\%).
5. Only with temperature fluctuations superposed can a further moderate improvement be achieved with additional microphysical assumptions such as a surface impedance limiting the growth/evaporation of the ice particles or the presence of heterogeneous nucleation on a few potent ice nuclei. With proper choices the model can represent the logarithm of the observed cirrus backscatter to better than $10 \%$ (which is within the uncertainty of the COBALD measurements of $\pm 8-10 \%$ of backscatter ratio at $870 \mathrm{~nm}$ ).

6. However, changes induced by the proper microphysical assumptions are of the same magnitude as changes induced by assumptions for temperature fluctuations referring to different meteorological conditions (clear sky, cloudy sky or all sky). Therefore, microphysical details cannot easily be retrieved from backscatter measurements, even when applied within the match technique.

7. The measured relative humidity can be successfully modeled for one of the two soundings, which shows $\mathrm{RH}_{\text {ice }}=80-120 \%$. However, the second sounding with $\mathrm{RH}_{\text {ice }}=120-140 \%$ cannot be modeled, irrespective of the scenario chosen. This suggests an erroneous $\mathrm{RH}_{\text {ice }}$ measurement, most likely due to a contamination by a rain droplet having impacted on the baffle or instrument housing of the chilled-mirror hygrometer.

Follow-up investigations are highly desirable, including matches with more favorable wind shear conditions and also studies with cloud-resolving 2-D or 3-D models to fully capitalize on the match measurement technique. 


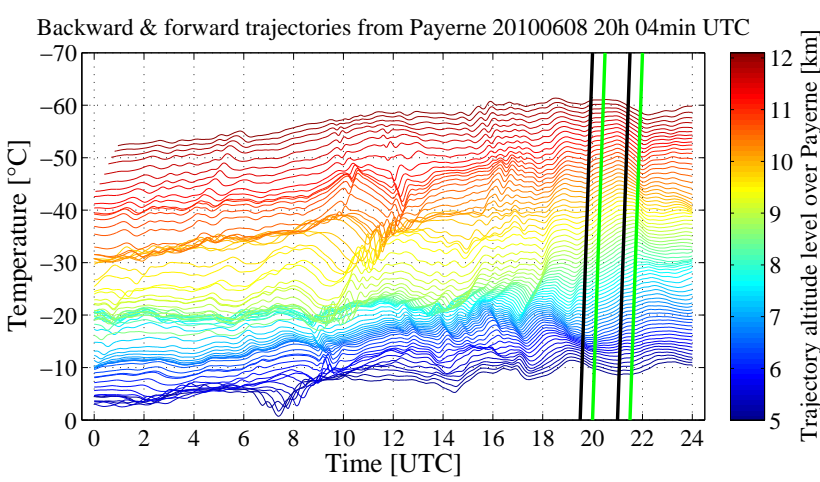

Figure A1. Temperature in degrees Celcius of ensemble of trajectories calculated from COSMO-7 analysis fields backward and forward in time starting from the flight track of the balloon launched at Payerne (Switzerland) using the LAGRANTO-based balloon trajectory model. Color coding is identical to that in Fig. 3. Balloon flight tracks from Payerne and Zurich shown as left and right green line, respectively. Black lines show both balloon paths displaced by 30 min (see text).

\section{Appendix A: microphysical analysis based on COSMO-7 trajectory fields without small-scale temperature fluctuations}

For the microphysical analysis an ensemble of trajectories has been calculated based on COSMO-7 analysis fields covering the altitude range of $5-12.6 \mathrm{~km}$ spaced at $100 \mathrm{~m}$ vertical intervals. The trajectories have been calculated forward and backward from the flight track of the balloon launched from the MeteoSwiss station at Payerne at 20:04 UTC on 8 June 2010. Figure A1 shows the temperature development along the trajectories for about one day based on COSMO-7 analysis fields, revealing an average cooling of the air masses by $\sim 7 \mathrm{~K}$ during this time period. Along the air parcel track Meteosat cloud images show that the air was free of clouds over the Atlantic at the west coast of Portugal but started forming the first high clouds over the Iberian Peninsula, and was enhanced when the air crossed the Pyrenees. The perturbations caused by crossing the Pyrenees are apparent in the increased trajectory wave activity around 10:00-12:00 UTC. The region between Payerne and Zurich is indicated by the balloon tracks as green lines in Fig. A1. This region is particularly interesting, because it marks the end of the overall cooling, showing some significant warming at altitudes above $9 \mathrm{~km}$, leading to a partial evaporation of the high clouds. Therefore, the measurements from Zurich took place in a situation with evaporating clouds, and a small error by COSMO-7 in the timing of warming renders the presentation of the observed clouds difficult.

Figure A2 shows model simulations for relative humidity with respect to ice $\left(\mathrm{RH}_{\text {ice }}\right)$, ice crystal number density $\left(n_{\text {ice}}\right)$, ice mixing ratio (defined as number density of water molecules condensed in ice divided by the number den-
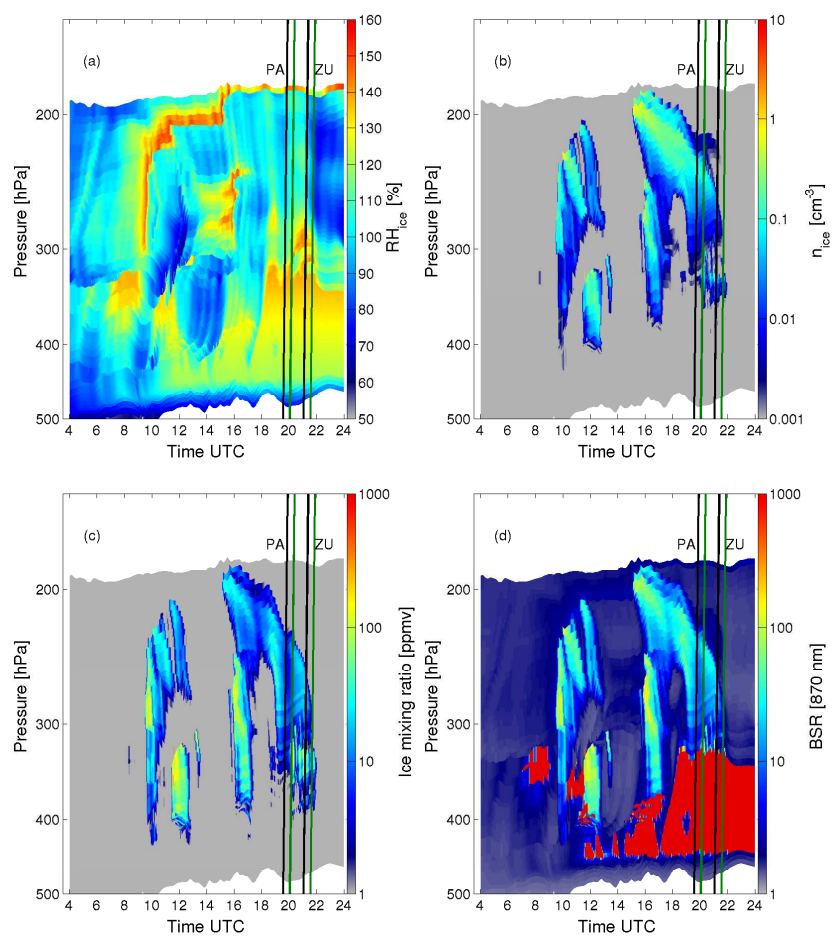

Figure A2. Detailed microphysics runs with column spectral model based on the original COSMO-7 analysis fields.(a) Relative humidity with respect to ice, (b) ice crystal number density and (c) ice mixing ratio (defined as number of water molecules condensed in ice per number of air molecules) and (d) aerosol backscatter ratio ( $870 \mathrm{~nm}$ wavelength). Green lines: flight tracks of balloons launched from Payerne ("PA") and Zurich ("ZU"). Black lines: positions shifted by half an hour upstream (to compensate for a COSMO warming time error). In (d), BSR $<5$ indicates aerosols with various amounts of $\mathrm{H}_{2} \mathrm{O}$ uptake (at different relative humidities), $5<\mathrm{BSR} \leq 100$ indicates cirrus clouds, and deep red coloring indicates mixed-phase clouds.

sity of air molecules) and aerosol backscatter ratio (BSR at $870 \mathrm{~nm}$ ) calculated by the ZOMM microphysical column model driven by winds, pressures and temperatures from COSMO-7 analysis fields. In the model, shortly after 07:00 UTC the first cloud is forming around $330 \mathrm{hPa}$ in ascending air masses above the Pyrenees. This cloud is at relatively low altitudes $(H<8 \mathrm{~km}, p>350 \mathrm{hPa})$ and high temperatures $(T>245 \mathrm{~K})$, clearly warmer than the homogeneous ice nucleation threshold of $235 \mathrm{~K}$ (Koop et al., 2000) and thus represented in the model as a supercooled liquid cloud with a very strong backscatter (red coloring, Fig. A2d). We emphasize that the modeled numerical value of the backscatter ratio of this liquid cloud is unrealistically high (BSR 1000), because ZOMM, though containing all relevant processes for cold cirrus clouds, does not describe processes in warmer mixed-phase clouds (coagulation and heterogeneous nucleation in liquid clouds are not implemented). 

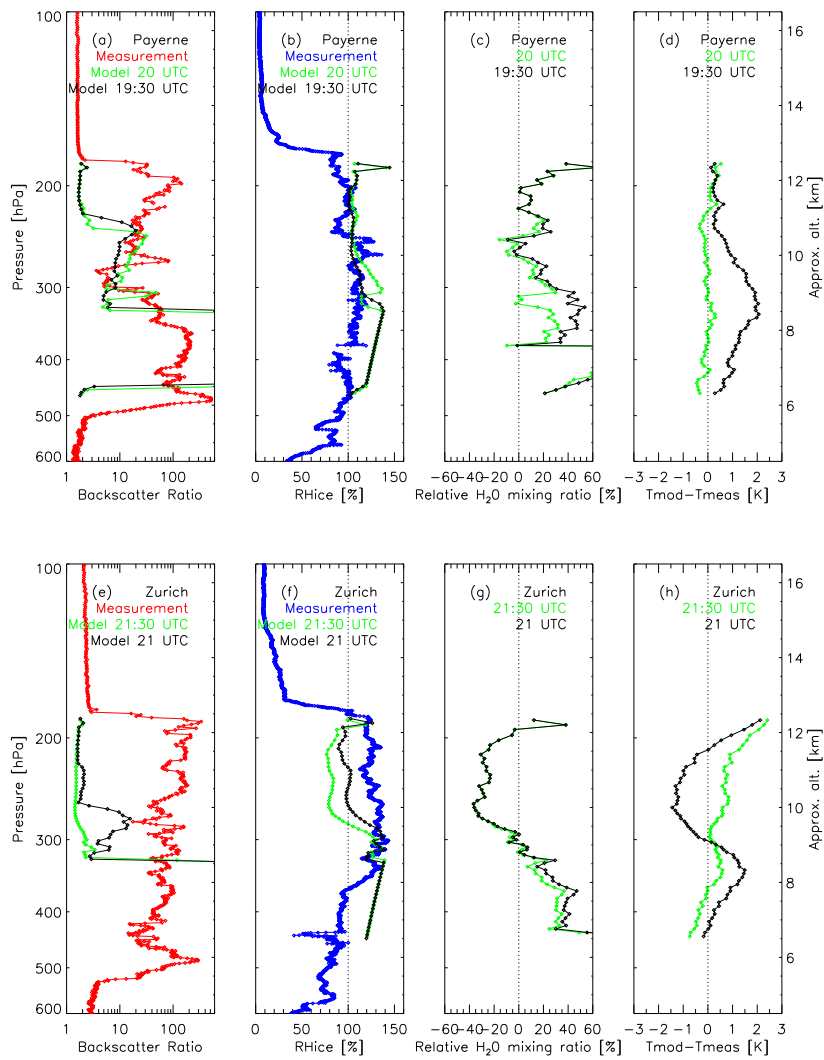

Figure A3. Comparison of the measurements with the model results calculated from trajectories in Fig. A2 based on original COSMO7 fields at the time of measurements (green lines) and half an hour upstream (black lines). Upper row: Payerne sounding. Lower panel: Zurich sounding. Quantities shown: (a, e) BSR at $870 \mathrm{~nm}$; $(\mathbf{b}, \mathbf{f}) \mathrm{RH}_{\text {ice }} ;(\mathbf{c}, \mathbf{g})$ percentage difference between model and measurement in water mixing ratio, $\left(\chi_{\mathrm{w}}\right.$, mod $\left.-\chi_{\mathrm{w} \text {,meas }}\right) / \chi_{\mathrm{w} \text {, meas }}$; and $(\mathbf{d}, \mathbf{h})$ difference in temperature between model and measurement.

At about 10:00 UTC, the model forms the first ice cloud in a thick layer between 230 and $280 \mathrm{hPa}(H \sim 9-10 \mathrm{~km})$. Ice crystal number densities in Fig. A2b remain low (mostly $n_{\text {ice }} \leq 0.1 \mathrm{~cm}^{-3}$ ), and almost vertical fall streaks to altitudes below the previous supercooled water cloud originate from large, quickly sedimenting ice particles. Forced by continuous upwelling all the way to Payerne, the model forms a succession of ice clouds at various altitudes $(H \sim 9-13 \mathrm{~km}$; $300 \mathrm{hPa}<p<150 \mathrm{hPa}$ ), which quickly sediment and/or sublimate, as well as persistent supercooled liquid clouds at $H \sim 6-9 \mathrm{~km}(450 \mathrm{hPa}<p<300 \mathrm{hPa})$.

As mentioned above, there is a pronounced warming between Payerne and Zurich. In the model, this leads to subsaturated conditions with $\mathrm{RH}_{\text {ice }} \sim 75 \%$ in the vicinity of the Zurich sounding (Fig. A2a). This causes an immediate suppression of further cloud formation and gravitational removal or sublimation of remaining ice particles until no ice is left (Fig. A2c). Only a thick supercooled liquid cloud at lower levels survives, and Meteosat cloud images confirm that the air masses completely clear up further downstream.

Figure $\mathrm{A} 3$ shows the resulting profiles of $\mathrm{BSR}$ and $\mathrm{RH}_{\text {ice }}$, comparing measured and calculated values (panels a, b, e and f) not only at the position of the balloon (green curves) but also with a position half an hour upstream (black curves). Since $\mathrm{RH}_{\text {ice }}=\chi_{\mathrm{w}} p / p_{\text {ice }}(T)$ is a function of both the local temperature (via the ice vapor pressure $p_{\text {ice }}(T)$ ) and the local water mixing ratio (via the water partial pressure $\chi_{\mathrm{w}} p$ ), we also compare measured and modeled temperatures (i.e., $T_{\text {mod }}-T_{\text {meas }}$, panels $\mathrm{d}$ and $\mathrm{h}$ ) and the relative water mixing ratio (i.e., $\left(\chi_{\mathrm{w} \text { mod }}-\chi_{\mathrm{w} \text { mod }}-\chi_{\mathrm{w} \text { meas }}\right) / \chi_{\mathrm{w} \text { meas }}$, panels $\mathrm{c}$ and g). The comparison with the Payerne sounding shows that the model manages to capture the clouds below $11 \mathrm{~km}$ very well, but misses the clouds between $\sim 11 \mathrm{~km}$ and the tropopause at $12.6 \mathrm{~km}$ altitude (Fig. A3a). Because $\mathrm{RH}_{\text {ice }}$ is more than $100 \%$ in the model, this deficiency must be due to a too fast gravitational removal, i.e., too large ice particles. The comparison with the Zurich sounding reveals a complete failure of the model, which has lost all ice clouds (Fig. A3e). In the altitude range $8-12.6 \mathrm{~km}(180-350 \mathrm{hPa})$ the COSMO temperatures are too warm by more than $2 \mathrm{~K}$ (Fig. A3h, green curve), indicating the timing error in the onset of the warming. This improves by displacing the temperatures upstream by 30 min (black curves), reducing the difference in $\mathrm{RH}_{\text {ice }}$, but does not establish the supersaturation observed by the Zurich sonde (Fig. A3f, blue curve). However, even with the displacement, the cirrus clouds above Zurich cannot be fully established (Fig. A3e).

\section{Appendix B: RH-dependent mass accommodation of $\mathrm{H}_{2} \mathrm{O}$ on ice}

The literature reports a broad range of values for the mass accommodation coefficient of water on ice (Stephens, 1983; Lin et al., 2002; Gierens et al., 2003; Magee et al., 2006). The surface nucleation rate depends critically on local saturation in the vicinity of the ice surface. For large ice particles and low gas-phase saturation, $\alpha$ can be less than 0.01 , whereas it approaches unity for small ice particles and high gas-phase saturation. ZOMM describes this in a simplified way relating $\alpha$ to the water saturation ratio directly over the ice surface $S=p_{\mathrm{w}}^{\text {surf }} / 4 p_{\mathrm{w}}^{\text {ice }}$ : for small $|S-1|$ growth/evaporation relies on the existence of defects (dislocations) on the ice surface, which lead to a continuous uptake (i.e., a constant accommodation coefficient $\alpha_{0}$ ); for large $|S-1|$, growth/evaporation proceeds via two-dimensional nucleation of new stable nuclei on the ice surface. This is modeled by classical nucleation theory: the Gibbs energy of 2-D disk of a monolayer with radius $r$ on the ice surface is given by

$$
G=\frac{\pi r^{2}}{A_{1}} k T \ln S+2 \pi r \Gamma
$$




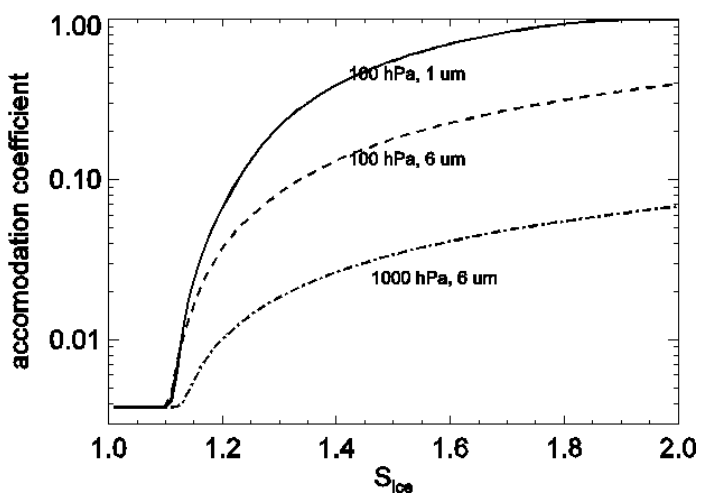

Figure B1. Mass accommodation coefficient as a function of saturation ratio over ice surface for different pressures and layer thicknesses.

where $A_{1}$ is a cross section of $\mathrm{H}_{2} \mathrm{O}$ molecules; $k$ is Boltzmann constant; $T$ is temperature; $S$ is the saturation ratio microscopically above the ice surface, which may deviate from the ambient relative humidity $\mathrm{RH}_{\text {ice }}$ (see below); and $\Gamma$ is the step energy per unit length.

The formation energy of the 2-D disk with critical size $r$, $G_{\mathrm{f}}$, can be obtained from $\mathrm{d} G / \mathrm{d} r=0$, resulting in

$G_{\mathrm{f}}=\frac{\pi A_{1} \Gamma^{2}}{k T \ln S}$.

The saturation ratio microscopically above the ice surface $S$ can be derived from considerations regarding the $\mathrm{H}_{2} \mathrm{O}$ molecule flux to/from the ice particle. When $N_{\mathrm{w}}$ is the number of $\mathrm{H}_{2} \mathrm{O}$ molecules diffusing to an ice crystal with radius $a$, this flux can be either described by the gas-phase diffusion equation (Pruppacher and Klett, 1997)

$\frac{d N_{\mathrm{w}}}{\mathrm{d} t}=4 \pi a \frac{D_{\mathrm{w}}}{1+\frac{4 D_{\mathrm{w}}}{\alpha a v}} n_{\mathrm{vap}}\left(\mathrm{RH}_{\mathrm{ice}}-1\right)$,

which takes account of the diffusion impedance in the gas volume, or by the Knudson diffusion

$\frac{d N_{\mathrm{w}}}{\mathrm{d} t}=4 \pi a^{2} \frac{\alpha \nu n_{\mathrm{vap}}(S-1)}{4}$,

which accounts for the surface impedance related to mass accommodation. Here, $D_{\mathrm{w}}$ is the gas-phase diffusion coefficient of water molecules in air, $\alpha$ is the mass accommodation coefficient of $\mathrm{H}_{2} \mathrm{O}$ on ice surface, $v$ the is thermal mean velocity of water molecules, and $n_{\text {vap }}$ is the equilibrium $\mathrm{H}_{2} \mathrm{O}$ vapor concentration over ice surface.

From equating Eqs. (B3) and (B4), the saturation ratio above the ice surface $S$ is given by

$S=\left(1+b \mathrm{RH}_{\text {ice }}\right) /(1+b)$,

where $b=4 D_{\mathrm{w}} /(\alpha a v)$ describes the reduction of the superor subsaturation from far away to the particle surface due to gas diffusive volume impedance. Equation (B5) describes the reduction of $\left|\mathrm{RH}_{\text {ice }}-1\right|$ to $|S-1|$ due to the impedance on ice surface by gas-phase diffusion.

The nucleation rate coefficient is then calculated as

$j=\frac{k T}{h} \exp \left[-\frac{\Delta F_{\mathrm{diff}}(T)}{k T}\right] \times n_{\mathrm{w}} \exp \left[-\frac{\Delta G_{\mathrm{f}}(T)}{k T}\right]$,

where $F_{\text {diff }}$ is the diffusion activation energy on the surface and $n_{\mathrm{w}}$ is the area number density of water molecules on an ice surface.

Finally, the number of surface layers nucleating within a time interval by surface nucleation depends on the surface area of the crystal plane, $A\left(=a^{2}\right)$; the time required to fill the layer via gas-phase diffusion, $\tau_{\mathrm{ml}}$; and the nucleation rate coefficient, $j$. From this the mass accommodation coefficient is approximated by the equation

$\alpha=1-\exp \left(-A j \tau_{\mathrm{ml}}-\alpha_{0}\right)$,

which exhibits the correct limits $\left(\alpha \rightarrow \alpha_{0}\right.$ for very small particles or small $\left|\mathrm{RH}_{\mathrm{ice}}-1\right|$, and $\alpha \rightarrow 1$ for very large $A$ or large $\left.\left|R H_{\text {ice }}-1\right|\right)$. The above treatment of monolayer nucleation leaves $\Gamma$, the step energy per unit length, and $\alpha_{0}$, the minimum mass accommodation coefficient, as the only unknowns. These are determined by fitting of laboratory experiments to data. Here we use the ice particle growth measurements for the cirrus regime performed by Magee et al. (2006), because they determined particularly low accommodations with $\alpha<0.01$. With this choice, maximum effects on the calculated cirrus cloud properties are expected (which are likely exaggerated; see Skrotzki et al. (2013), who determined $\alpha=0.7_{-0.5}+0.3$ ). The resulting dependence of $\alpha$ on the ambient relative humidity $\mathrm{RH}_{\text {ice }}$ is depicted in Fig. B1, showing that larger particle sizes have indeed smaller $\alpha$ in the nucleation regime. As the ice crystals grow to larger sizes, $\alpha$ decreases because the gas diffusion impedance diminishes the super- or subsaturation directly above the crystal surface, $|S-1|$, in comparison to the ambient $\left|\mathrm{RH}_{\text {ice }}-1\right|$.

\section{Appendix C: active site theory for heterogeneous ice nucleation}

From classical nucleation theory (Pruppacher and Klett, 1997), the heterogeneous rate coefficient $J_{\text {het }}$ for ice nucleation (units of $\mathrm{cm}^{-2} \mathrm{~s}^{-1}$ ) is formulated as

$$
\begin{gathered}
j_{\text {het }}(T)=\frac{k T}{h} \exp \left[-\frac{\Delta F_{\text {diff }}(T)}{k T}\right] \times n_{\mathrm{w}} \\
\exp \left[-\frac{\Delta G_{\mathrm{f}}(T) f_{\text {het }}}{k T}\right],
\end{gathered}
$$

where $k$ and $h$ are the Boltzmann and the Planck constant, respectively, and $n_{\mathrm{w}}$ is the number density of water molecules at the interface between water and the ice nucleus (taken as 
$10^{15} \mathrm{~cm}^{-2}$ ). The diffusion activation energy $\Delta \mathrm{F}_{\text {diff }}$ and the Gibbs free energy $\Delta \mathrm{G}_{\mathrm{f}}$ are parameterized according to Zobrist et al. (2007). The ice saturation ratio $S$ in the liquid enters into the calculation of $\Delta \mathrm{G}_{\mathrm{f}}$ and is defined for immersion freezing as $S=p_{\mathrm{w}}^{\mathrm{liq}}(T) / p_{\mathrm{w}}^{\text {ice }}(T)$. Vapor pressures of liquid water and ice are calculated following Murphy and Koop (2005). The compatibility function, $F_{\text {het }}<1$, discriminates homogeneous and heterogeneous nucleation, as it describes the reduction of the energy barrier $\Delta \mathrm{G}_{\mathrm{f}}$, which needs to be overcome to form a critical ice embryo:

$f_{\text {het }}=\frac{1}{4}(2+\cos \gamma)(1-\cos \gamma)^{2}$.

The contact angle $\gamma$ between the ice embryo and the ice nucleus can vary from 0 to $180^{\circ}$, which for small contact angles results in nucleation starting as soon as the vapor is saturated, whereas for large contact angles heterogeneous nucleation is not much favored over homogeneous nucleation. Similar to Engel et al. (2013), we will utilize a parameterization for ice nucleation on mineral dust (Arizona test dust, ATD) obtained by Marcolli et al. (2007) from freezing experiments. They observed heterogeneous nucleation over a broad temperature range, and concluded that the ability to nucleate ice varies between different ATD particles, leading to the following "active sites" occurrence probability:

$P_{\text {as }}=10^{-5} \operatorname{deg}^{-1} \times \exp \left(\frac{-51^{\circ}}{\gamma-46^{\circ}}\right)$.

Active sites are surface inhomogeneities such as steps or cavities, or chemical or electrical inhomogeneities, which are assumed to initiate ice nucleation (Pruppacher and Klett, 1997).
Table C1. Relative error (in percent, italicized numbers) given by $M$ in Eq. (3) between backscatter measurement and model results for the runs with the best fluctuation member for the all-sky scenario. Results are shown for two values of the mass accommodation coefficient ( $\alpha=1$ and $f(\mathrm{RH})$ ) and five values of heterogeneous ice nuclei number densities $\left(n_{\mathrm{IN}}\right)$

\begin{tabular}{cccc}
\hline & $n_{\mathrm{IN}}\left[\mathrm{L}^{-1}\right]$ & Payerne & Zurich \\
\hline \multirow{4}{*}{$\alpha=1$} & 0 & -21 & -31 \\
& 10 & +1 & -8 \\
& 20 & -37 & -53 \\
& 50 & -40 & -57 \\
& 100 & -41 & -52 \\
\hline \multirow{4}{*}{$\alpha=f(\mathrm{RH})$} & 0 & +5 & +2 \\
& 10 & -12 & -8 \\
& 20 & -28 & -43 \\
& 50 & -29 & -51 \\
& 100 & -27 & -43 \\
\hline
\end{tabular}

We have performed additional case studies with varying IN number $\left(20,50\right.$ and $100 \mathrm{~L}^{-1}$, in addition to the $10 \mathrm{~L}^{-1} \mathrm{al}-$ ready addressed in the main text) and show these in Table $\mathrm{C} 1$. While the agreement with the measurements is best for low or vanishing ice nucleus densities $\left(n_{\mathrm{IN}}=0-10 \mathrm{~L}^{-1}\right.$ depending of the choice of $\alpha$ ), the agreement worsens for increasing $n_{\mathrm{IN}}$. The reason for this is that less and less homogeneous nucleation takes place; therefore the resulting ice particles are too few in number and too large in size and fall out before the measurement site is reached. This behavior reverses when $n_{\mathrm{IN}}$ increases from 50 to $100 \mathrm{~L}^{-1}$, because then the number density of ice particles is high enough for some ice particles to be able to survive longer. These additional calculations corroborate the conclusions drawn in the paper. 
Acknowledgements. We gratefully acknowledge funding by COST and GAW-CH: within COST (European Cooperation in Science and Technology) the match forecasts and measurements were supported by the Swiss State Secretariat for Education and Research (serial no. C08.0037, Lagrangian Measurements and Modeling of Cirrus Clouds (LAMMOC)) under action ES0604 "Atmospheric Water Vapour in the Climate System (WaVaCS)". Within the "Swiss GAW (GAW-CH) Programme 2010-2013" a large part of the data evaluation and simulation was performed as part of the project "Assessment of high altitude cloud characteristics by in-situ and remote sensing techniques". T. Peter was a visiting scientist with the Cooperative Institute for Research in Environmental Sciences (CIRES) and hosted by the Chemical Sciences Division of NOAA Earth System Research Laboratory (Boulder, CO), and gratefully acknowledges fruitful scientific discussions with D. Fahey, R.S. Gao, K. Rosenlof, D. Murphy and A. R. Ravishankara, as well as E. Jensen from NASA Ames. We also want to thank A. Gettelman from NCAR and U. Lohmann from ETH Zurich for help through their reading of the original manuscript, as well as both anonymous reviewers for their careful reading of the manuscript and for their suggestions and critical questions, which helped us to improve our paper. Finally, we thank D. Lüthi and H. Richner from ETH Zurich for providing COSMO data and radar and ground station data, respectively, and Rolf Maag from Meteolabor (Wetzikon) for support with the SnowWhite sensors.

Edited by: M. Petters

\section{References}

Bartels-Rausch, T., Bergeron, V., Cartwright, J. H. E., Escribano, R., Finney, J. L., Grothe, H., Gutierrez, P. J., Haapala, J., Kuhs, W. F., Pettersson, J. B. C., Price, S. D., Sainz-Diaz, C. I., Stokes, D. J., Strazzulla, G., Thomson, E. S., Trinks, H., and Uras-Aytemiz, N.: Ice structures, patterns, and processes: A view across the icefields, Revs. Mod. Phys., 84, 885-944, doi:10.1103/RevModPhys.84.885, 2012.

Bock, O., Bosser, P., Bourcy, T., David, L., Goutail, F., Hoareau, C., Keckhut, P., Legain, D., Pazmino, A., Pelon, J., Pipis, K., Poujol, G., Sarkissian, A., Thom, C., Tournois, G., and Tzanos, D.: Accuracy assessment of water vapour measurements from in situ and remote sensing techniques during the DEMEVAP 2011 campaign at OHP, Atmos. Meas. Tech., 6, 2777-2802, doi:10.5194/amt-6-2777-2013, 2013.

Bohren, C. F. and Huffman, D.: Absorption and scattering of light by small particles, New York, Wiley-Interscience, 530 pp., 1983.

Brabec, M., Wienhold, F. G., Luo, B. P., Vömel, H., Immler, F., Steiner, P., Hausammann, E., Weers, U., and Peter, T.: Particle backscatter and relative humidity measured across cirrus clouds and comparison with microphysical cirrus modelling, Atmos. Chem. Phys., 12, 9135-9148, doi:10.5194/acp-12-9135-2012, 2012.

Chen, T., Rossow, W., and Zhang, Y.: Radiative Effects of CloudType Variations, J. Climate, 13, 264-286, 2000.

Comstock, J., Ackerman, T., and Turner, D.: Evidence of high ice supersaturation in cirrus clouds using ARM Raman lidar measurements, Geophys. Res. Lett., 31, L11106, doi:10.1029/2004GL019705, 2004.
Corti, T. and Peter, T.: A simple model for cloud radiative forcing, Atmos. Chem. Phys., 9, 5751-5758, doi:10.5194/acp-9-57512009, 2009.

Cziczo, D. J., Froyd, K. D., Hoose, C., Jensen, E. J., Diao, M., Zondlo, M. A., Smith, J. B., Twohy, C. H., and Murphy, D. M.: Clarifying the Dominant Sources and Mechanisms of Cirrus Cloud Formation, Science, 340, 1320-1324, doi:10.1126/science.1234145, 2013.

DeMott, P., Cziczo, D., Prenni, A., Murphy, D., Kreidenweis, S., Thomson, D., Borys, R., and Rogers, D.: Measurements of the concentration and composition of nuclei for cirrus formation, $\mathrm{P}$. Natl. Acad. Sci. USA, 100, 14655-14660, 2003.

DeMott, P., Prenni, A. J., Liu, X., Kreidenweis, S. M., Petters, M. D., Twohy, C. H., Richardson, M. S., Eidhammer, T., and Rogers, D. C.: Predicting global atmospheric ice nuclei distributions and their impacts on climate, P. Natl. Acad. Sci., 107, 11217-11222, 2010.

Dionisi, D., Keckhut, P., Hoareau, C., Montoux, N., and Congeduti, F.: Cirrus crystal fall velocity estimates using the Match method with ground-based lidars: first investigation through a case study, Atmos. Meas. Tech., 6, 457-470, doi:10.5194/amt-6-457-2013, 2013.

Engel, I.: Trajectory Modelling of Match Balloon Soundings for Cirrus Cloud Characterisation, Diploma thesis, University of Münster, Faculty of Geosciences, Institute of Landscape Ecology, http://www.uni-muenster.de/Klima/lehre/ diplomarbeiten.shtml (last access: 1 July 2014), 2009.

Engel, I., Luo, B. P., Pitts, M. C., Poole, L. R., Hoyle, C. R., Grooß, J.-U., Dörnbrack, A., and Peter, T.: Heterogeneous formation of polar stratospheric clouds - Part 2: Nucleation of ice on synoptic scales, Atmos. Chem. Phys., 13, 10769-10785, doi:10.5194/acp13-10769-2013, 2013.

Fahey, D. W., Gao, R.-S., Möhler, O., Saathoff, H., Schiller, C., Ebert, V., Krämer, M., Peter, T., Amarouche, N., Avallone, L. M., Bauer, R., Bozóki, Z., Christensen, L. E., Davis, S. M., Durry, G., Dyroff, C., Herman, R. L., Hunsmann, S., Khaykin, S. M., Mackrodt, P., Meyer, J., Smith, J. B., Spelten, N., Troy, R. F., Vömel, H., Wagner, S., and Wienhold, F. G.: The AquaVIT-1 intercomparison of atmospheric water vapor measurement techniques, Atmos. Meas. Tech. Discuss., 7, 3159-3251, doi:10.5194/amtd-73159-2014, 2014.

Field, P. R., Heymsfield, A. J., and Bansemer, A.: A Test of Ice Self-Collection Kernels Using Aircraft Data, J. Atmos. Sci., 63, 651-666, 2006.

Fritts, D. C. and Alexander, M. J.: Gravity wave dynamics and effects in the middle atmosphere, Rev. Geophys., 41, 1003, doi:10.1029/2001RG000106, 2003.

Fu, Q.: A new parameterization of an asymmetry factor of cirrus clouds for climate models, J. Atmos. Sci., 64, 4140-4150, 2007.

Fueglistaler, S., Luo, B. P., Buss, S., Wernli, H., Voigt, C., Müller, M., Neuber, R., Hostetler, C. A., Poole, L. R., Flentje, H., Fahey, D. W., Northway, M. J., and Peter, T.: Large NAT particle formation by mother clouds: Analysis of SOLVE/THESEO-2000 observations, Geophys. Res. Lett., 29, 1610, doi:10.1029/2001GL014548, 2002.

Fujiwara, M., Shiotani, M., Hasebe, F., Vömel, H., Oltmans, S. J., Ruppert, P. W., Horinouchi, T., and Tsuda, T.: Performance of the meteolabor "Snow White" chilledmirror hygrometer in the 
tropical troposphere: Comparisons with the Vaisala RS80 A/HHumicap sensors, J. Atmos. Ocean. Tech., 20, 1534-1542, 2003.

Fusina, F. and Spichtinger, P.: Cirrus clouds triggered by radiation, a multiscale phenomenon, Atmos. Chem. Phys., 10, 5179-5190, doi:10.5194/acp-10-5179-2010, 2010.

Fusina, F., Spichtinger, P., and Lohmann, U.: The impact of ice supersaturated regions and thin cirrus on radiation in the mid latitudes, J. Geophys. Res., 112, D24S14, doi:10.1029/2007JD008449, 2007.

Gallice, A., Wienhold, F. G., Hoyle, C. R., Immler, F., and Peter, T.: Modeling the ascent of sounding balloons: derivation of the vertical air motion, Atmos. Meas. Tech., 4, 2235-2253, doi:10.5194/amt-4-2235-2011, 2011.

Gettelman, A., Fetzer, E., Eldering, A., and Irion, F.: The global distribution of supersaturation in the upper troposphere from the Atmospheric Infrared Sounder, J. Climate, 19, 6089-6103, 2006.

Gierens, K. and Spichtinger, P.: On the size distribution of icesupersaturated regions in the upper troposphere and lowermost stratosphere, Ann. Geophys., 18, 499-504, doi:10.1007/s00585000-0499-7, 2000.

Gierens, K. M., Monier, M., and Gayet, J.-F.: The deposition coefficient and its role for cirrus clouds, J. Geophys. Res., 108, 4069, doi:10.1029/2001JD001558, 2003.

Gultepe, I. and Starr, D. O.: Dynamical Structure and Turbulence in Cirrus Clouds: Aircraft Observations during FIRE, J. Atmos. Sci., 52, 4159-4182, 1995.

Hasebe, F., Fujiwara, M., Nishi, N., Shiotani, M., Vömel, H., Oltmans, S., Takashima, H., Saraspriya, S., Komala, N., and Inai, Y.: In situ observations of dehydrated air parcels advected horizontally in the Tropical Tropopause Layer of the western Pacific, Atmos. Chem. Phys., 7, 803-813, doi:10.5194/acp-7-803-2007, 2007.

Houze, R.: Cloud Dynamics, Academic Press, San Diego, CA, USA, 573 pp., 1993.

Hoyle, C., Luo, B. P., and Peter, T.: The origin of high ice crystal number densities in cirrus clouds, J. Atmos. Sci., 62, 2568-2579, 2005.

Inai, Y., Hasebe, F., Fujiwara, M., Shiotani, M., Nishi, N., Ogino, S.-Y., Vömel, H., Iwasaki, S., and Shibata, T.: Dehydration in the tropical tropopause layer estimated from the water vapor match, Atmos. Chem. Phys., 13, 8623-8642, doi:10.5194/acp-13-86232013, 2013.

Jensen, E. and Toon, O.: Ice nucleatin in the upper troposphere: Sensitivity to aerosol number density, temperature, and cooling rate, Geophys. Res. Lett., 21, 2019-2022, 1994.

Jensen, E., Smith, J., Pfister, L., Pittman, J., Weinstock, E., Sayres, D., Herman, R., Troy, R., Rosenlof, K., Thompson, T., Fridlind, A., Hudson, P., Cziczo, D., Heymsfield, A., Schmitt, C., and Wilson, J.: Ice supersaturations exceeding $100 \%$ for cirrus formation and dehydration, Atmos. Chem. Phys., 5, 851-862, doi:10.5194/acp-5-851-2005, 2005.

Koop, T., Luo, B. P., Tsias, A., and Peter, T.: Water activity as the determinant for homogeneous ice nucleation in aqueous solutions, Nature, 406, 611-614, 2000.

Krämer, M., Schiller, C., Afchine, A., Bauer, R., Gensch, I., Mangold, A., Schlicht, S., Spelten, N., Sitnikov, N., Borrmann, S., de Reus, M., and Spichtinger, P.: Ice supersaturations and cirrus cloud crystal numbers, Atmos. Chem. Phys., 9, 3505-3522, doi:10.5194/acp-9-3505-2009, 2009.
Krieger, U., Mössinger, J., Luo, B., Weers, U., and Peter, T.: Measurement of the Refractive Indices of $\mathrm{H}_{2} \mathrm{SO}_{4}-\mathrm{HNO}_{3}-\mathrm{H}_{2} \mathrm{O}$ Solutions to Stratospheric Temperatures, Appl. Optics, 39, 36913703, doi:10.1364/AO.39.003691, 2000.

Lin, R.-F., Starr, D. O. C., DeMott, P. J., Cotton, R., Sassen, K., Jensen, E., Kärcher, B., and Liu, X.: Cirrus parcel model comparison project phase 1: The critical components to simulate cirrus initiation explicity, J. Atmos. Sci., 59, 2305-2329, 2002.

Luo, B. P., Voigt, C., Fueglistaler, S., and Peter, T.: Extreme NAT supersaturations in mountain wave ice PSCs: A clue to NAT formation, J. Geophys. Res., 108, 4441, doi:10.1029/2002JD003104, 2003.

Lynch, D., Sassen, K., Starr, D., and Stephens, G. (Eds.): Cirrus, Oxford University Press, USA, 2002.

MacKenzie, A. R. and Haynes, P. H.: The influence of surface kinetics on the growth of stratospheric ice crystals, J. Geophys. Res. 97, 8057-8064, 1992

Magee, N., Moyle, A. M., and Lamb, D.: Experimental determination of the deposition coefficient of small cirrus-like ice crystals near -50 deg C., Geophys. Res. Lett., 33, L17813, doi:10.1029/2006GL026665, 2006.

Marcolli, C., Gedamke, S., Peter, T., and Zobrist, B.: Efficiency of immersion mode ice nucleation on surrogates of mineral dust, Atmos. Chem. Phys., 7, 5081-5091, doi:10.5194/acp-7-50812007, 2007.

Marsham, J. H. and Dobbie, S.: The effects of wind shear on cirrus: A large-eddy model and radar case-study, Q. J. Roy. Meteor. Soc., 131, 2937-2955, doi:10.1256/qj.04.122, 2005.

Mason, B.: The role of clouds in the radiative balance of the atmosphere and their effects on climate, Contemp. Phys., 43, 1-11, doi:10.1080/00107510110084075, 2002.

Meteolabor, data sheet SnowWhite frostpoint mirror, http://www.meteolabor.ch/en/meteorological-instruments/ radiosondierung-en/ (last access: 1 July 2014), 2013.

Mishchenko, M.: Light scattering by randomly oriented axially symmetric particles, J. Opt. Soc. Am., 8, 871-882, 1991.

Murphy, D. M. and Koop, T.: Review of the vapour pressures of ice and supercooled water for atmospheric applications, Q. J. Roy. Meteor. Soc., 131, 1565, doi:10.1256/qj.04.94, 2005.

Nousiainen, T. and McFarquhar, G.: Light scattering by quasispherical ice crystals, J. Atmos. Sci., 61, 2229-2248, 2004.

Ovarlez, J. P. v. V., Sachse, G., Vay, S., Schlager, H., and Ovarlez, H.: Comparison of water vapor measurements from POLINAT 2 with ECMWF analyses in high humidity conditions, J. Geophys. Res., 105, 3737-3744, 2000.

Peter, T., Marcolli, C., Spichtinger, P., Corti, T., Baker, M. B., and Koop, T.: When dry air is too humid, Science, 314, 1399-1400, 2006.

Peter, T., Krämer, M., and Möhler, O.: Upper tropospheric humidity: A report on an international workshop. SPARC Newsletter, No. 30, SPARC Office, Toronto, Ontario, Canada, 9-15, available at: http://www.sparc-climate.org/fileadmin/customer/6_ Publications/Newsletter_PDF/30_SPARCnewsletter_Jan 2008. pdf (last access: 1 July 2014), 2008.

Pratte, P., van den Bergh, U., and Rossi, M. J.: The kinetics of $\mathrm{H}_{2} \mathrm{O}$ vapor condensation and evaporation on different types of ice in the range 130-210 K, J. Phys. Chem. A, 110, 3042-3058, doi:10.1021/jp053974s, 2006. 
Pruppacher, H. and Klett, J.: Microphysics of clouds and precipitation, Kluwer Academic Publisher, Dordrecht/Boston/London, 1997.

Rex, M.: Stratosphärische Ozonabbauraten aus den Ozonsondendaten der EASOE-Kampagne, Master's thesis, Georg-AugustUniversität Göttingen, available at: http://epic.awi.de/3403/1/ Wit9999a.pdf (last access: 1 July 2014), 1993.

Rex, M., Harris, N. R. P., van der Gathen, P., Lehmann, R., Braathen, G. O., Reimer, E., Beck, A., Chipperfield, M. P., Alfier, R., Allaart, M., O'Connor, F., Dier, H., Dorokhov, V., Fast, H., Gil, M., Kyrö, E., Litynska, Z., Mikkelsen, I. S., Molyneux, M. G., Nakane, H., Notholt, J., Rummukainen, M., Viatte, P., and Wenger, J.: Prolonged stratospheric ozone loss in the 199596 Arctic winter, Nature, 389, 835-838, 1997.

Rex, M., van der Gathen, P., Braathen, G. O., Harris, N. R. P., Reimer, E., Beck, A., Alfier, R., Krüger-Carstensen, R., Chipperfield, M., de Backer, H., Balis, D., O'Connor, F., Dier, H., Dorokhov, V., Fast, H., Gamma, A., Gil, M., Kyrö, E., Litynska, Z., Mikkelsen, S., Molyneux, M., Murphy, G., Reid, S. J., Rummukainen, M., and Zerefos, C.: Chemical ozone loss in the Arctic winter 1994/95 as determined by the Match technique, J. Atmos. Chem., 32, 35-59, 1999.

Rollins, A. W., Thornberry, T. D., Gao, R. S., Smith, J. B., Sayres, D. S., Sargent, M. R., Schiller, C., Krämer, M., Spelten, N., Hurst, D. F., Jordan, A. F., Hall, E. G., Vömel, H., Diskin, G. S., Podolske, J. R., Christensen, L. E., Rosenlof, K. H., Jensen, E. J., and Fahey, D. W.: Evaluation of UT/LS hygrometer accuracy by intercomparison during the NASA MACPEX mission, J. Geophys. Res. Atmos., 119, 1915-1935, doi:10.1002/2013JD020817, 2014.

Rosen, J. and Kjome, N.: Backscattersonde: a new instrument for atmospheric aerosol research, Appl. Optics, 30, 1552-1561, 1991.

Sadtchenko, V., Brindza, M., Chonde, M., Palmore, B., and Eom, R.: The vaporization rate of ice at temperatures near its melting point, J. Chem. Phys., 121, 11980-11992, doi:10.1063/1.1817820, 2004.

Skrotzki, J.: High-accuracy multiphase humidity measurements using TDLAS: Application to the investigation of ice growth in simulated cirrus clouds, PhD Thesis, Faculties for the Natural Sciences and for Mathematics, University of Heidelberg, Heidelberg, Germany, 140 pp., available at: http://archiv. ub.uni-heidelberg.de/volltextserver/13141/ (last access: 1 July 2014), 2012.

Skrotzki, J., Connolly, P., Schnaiter, M., Saathoff, H., Möhler, O., Wagner, R., Niemand, M., Ebert, V., and Leisner, T.: The accommodation coefficient of water molecules on ice - cirrus cloud studies at the AIDA simulation chamber, Atmos. Chem. Phys., 13, 4451-4466, doi:10.5194/acp-13-4451-2013, 2013.

Soden, B. J.: The impact of tropical convection and cirrus on upper tropospheric humidity: A Lagrangian analysis of satellite measurements, Geophys. Res. Lett., 31, L20104, doi:10.1029/2004GL020980, 2004.
Solomon, S., Qin, D., Manning, M., Chen, Z., Marquis, M., Averyt, K. B., Tignor, M., and Miller, H. L. (Eds.): Climate Change 2007: The Physical Science Basis. Contribution of Working Group I to the Fourth Assessment Report of the Intergovernmental Panel on Climate Change, Cambridge University Press, Cambridge, UK and New York, NY, USA, 2007.

Spichtinger, P.: Shallow cirrus convection - a source for ice supersaturation, Tellus A, accepted, 2014.

Spichtinger, P. and Gierens, K.: Modelling of cirrus clouds - Part 1a: Model description and validation, Atmos. Chem. Phys., 9, 685-706, doi:10.5194/acp-9-685-2009, 2009a.

Spichtinger, P. and Gierens, K. M.: Modelling of cirrus clouds - Part 2: Competition of different nucleation mechanisms, Atmos. Chem. Phys., 9, 2319-2334, doi:10.5194/acp-9-2319-2009, 2009b.

Spichtinger, P., Gierens, K., Leiterer, U., and Dier, H.: Ice supersaturation in the tropopause region over Lindenberg, Germany, Meteorol. Z., 12, 143-156, 2003a.

Spichtinger, P., Gierens, K., and Read, W.: The global distribution of ice-supersaturated regions as seen by the microwave limb sounder, Q. J. Roy. Meteor. Soc., 129, 3391-3410, 2003b.

Spichtinger, P., Gierens, K., and Dörnbrack, A.: Formation of ice supersaturation by mesoscale gravity waves, Atmos. Chem. Phys., 5, 1243-1255, doi:10.5194/acp-5-1243-2005, 2005.

Stephens, G. L.: The influence of radiative transfer on the mass and heat budgets of ice crystals falling in the atmosphere, J. Atmos. Sci., 40, 1729-1739, 1983.

von der Gathen, P., Rex, M., Harris, N. R. P., Lucic, D., Knudsen, B. M., Braathen, G. O., Debacker, H., Fabian, R., Fast, H., Gil, M., Kyrö, E., Mikkelsen, I. S., Rummukainen, M., Stähelin, J., and Varotsos, C.: Observational evidence for chemical ozone depletion over the Arctic in winter 1991-92, Nature, 375, 131-134, 1995.

Vömel, H., David, D., and Smith, K.: Accuracy of tropospheric and stratospheric water vapor measurements by cryogenic frost point hygrometer: Instrumental details and observations, J. Geophys. Res., 112, D08305, doi:10.1029/2006JD007224, 2007.

Wernli, H. and Davies, H.: A Lagrangian-based analysis of extratropical cyclones. I: The method and some applications, Q. J. Roy. Meteor. Soc., 123, 467-489, 1997.

Wienhold, F. G., COBALD Data Sheet, available at: http://www.iac.ethz.ch/groups/peter/research/Balloon_ soundings/COBALD_sensor (last access: 1 July 2014), 2012.

Wood, S. E., Baker, M. B., and Calhoun, D.: New model for the vapor growth of hexagonal ice crystals in the atmosphere, J. Geophys. Res., 106, 4845-4870, doi:10.1029/2000JD900338, 2001.

Zobrist, B., Koop, T., Luo, B. P., Marcolli, C., and Peter, T.: Heterogeneous ice nucleation rate coefficient of water droplets coated by a nonadecanol monolayer, J. Phys. Chem. C., 111, 21492155, doi:10.1021/jp066080w, 2007. 